\title{
5.Sınıf İngilizce Ders Kitabında Yer Alan Değerler ve İngilizce Öğretmenlerinin Değerler Eğitimi Konusundaki Görüşleri*
}

\section{Values Covered in the 5th Grade English Textbook and English Teachers' Viwes on Values Education**}

\author{
Saime GÜL, Öğretmen. \\ Erbaa İmam Hatip Ortaokulu, Tokat / Türkiye \\ saime_gul05@hotmail.com \\ https://orcid.org/0000-0002-8417-2277 \\ F. Özge MAVIŞ SEVİM, Sorumlu Yazar, Dr. Öğr. Üyesi. \\ Tokat Gaziosmanpaşa Üniversitesi, Eğitim Fakülesi, Tokat / Türkiye. \\ ozge.mavis@gop.edu.tr \\ https://orcid.org/0000-0002-4120-5374
}

ISSN: 1303-880X

e-ISSN: 2667-7504

http://ded.dem.org.tr

Makale Türü / Article Type:

Araştırma Makalesi / Research Article

Geliş Tarihi / Received Date: 27.06.2021

Kabul Tarihi / Accepted Date: 03.11. 2021

Yayın Tarihi / Published Date: 25.12.2021

Tr/En: $\operatorname{Tr}$

Intihal / Plagiarism: Bu makale, en az iki hakem tarafindan incelendi ve intihal içermediği teyit edildi. / This article has been reviewed by at least two referees and scanned via a plagiarism software.
Atıf/Citation: Maviş Sevim, F.Ö. \& Gül, S. (2021). 5.Sınıf İngilizce ders kitabında yer alan değerler ve İngilizce öğretmenlerinin değerler eğitimi konusundaki görüşleri. $D e-$ gerler Ĕgitimi Dergisi,19 (42), s.187-226 https://doi.org/10.34234/ded.958187

* Bu çalışma, F. Özge MAVİŞ SEVİM danışmanlığında Saime GÜL tarafından gerçekleştirilmiş olan tezsiz yüksek lisans projesinin bir bölümünden oluşmaktadır.

**This study consists of a part of the non-thesis master's project carried out by Saime GÜL under the supervision of F. Özge MAVIŞ SEVİM. 
Öz: Bu araştırmada ilk olarak Ortaokul 5. sınıf İngilizce Happy English Ders Kitabı, aktarılan değerler bağlamında analiz edilmiştir. Araştırmanın bu kısmında doküman analizi tekniği kullanılmış ve veriler betimsel analiz yöntemiyle analiz edilmiştir. Analizler sonucunda arkadaşlık, sağlıklı yaşam, sporseverlik, yardımseverlik ve nezaket gibi değerlere sıklıkla yer verildiği, Milli Eğitim Bakanlığının İngilizce öğretim programında öne çıkardığı adalet, dürüstlük, sevgi, sayg1, vatanseverlik ve özdenetim gibi değerlere ilişkin verilere çok az rastlandığı tespit edilmiştir. Araştırmanın diğer amacı, İngilizce öğretmenlerinin 5.s1nıf ders kitaplarındaki değerler eğitimiyle ilgili görüşlerini ortaya koymaktır. Araştırmanın çalışma grubunu 2020-2021 eğitim-öğretim yılında Türkiye genelinde Milli Eğitim Bakanlığına bağl eğitim kurumlarında çalışan 40 İngilizce öğretmeni oluşturmaktadır. Veri toplama aracı olarak yarı-yapılandırılmış anket formları kullanılmış ve verilerin analizinde betimsel analizden yararlanılmıştır. Çalışmanın sonuçlarına göre öğretmenler farklı kültürleri tanıma, anlama ve sayg1, kendi milli ve manevi değerlerimizi kazanmayı sağlama, kişilik/karakter gelişimi sağlama ve derse karşı ilgiyi artırma gibi yönlerden değerler eğitiminin gerekli olduğunu düşünmektedirler. Araştırmaya katılan öğretmenlerin büyük çoğunluğunun kitaptaki değerler eğitimine yönelik etkinlik, içerik ve görsellerin yeterli olmadığı görüşünde olduğu tespit edilmiştir. Ders kitaplarının yetersizliği/etkinlik eksikliği, ailelerden destek alamama, bazı değerlerin içselleştirilmesinin ve uygulanmasının zor olması ve müfredat yoğunluğu gibi nedenlerden dolayı öğretmenler, değerler eğitimi yaparken zorlandıklarını belirtmişlerdir ve bu sorunların çözümüne ilişkin çeşitli önerilerde bulunmuşlardır.

Anahtar Kelimeler: Değer, Değerler Eğitimi, İngilizce Kitabı, İngilizce Öğretmenleri.

\section{$\&$}

Abstract: In this study, firstly, $5^{\text {th }}$ grade English Textbook, Happy English was analyzed in the context of transferring values. In this part of the research, the document analysis technique was used and the data were analyzed with the descriptive analysis method. As a result of the analyses, it has been determined that values such as friendship, healthy life, sportsmanship, helpfulness and kindness are frequently included, and that there are very few data on values such as justice, honesty, love, respect, patriotism and self-control, which the Ministry of National Education emphasizes in the English curriculum. Another aim of the 
study is to reveal the opinions of English teachers about values education in $5^{\text {th }}$ grade textbooks. The study group of the research consists of 40 English teachers working in educational institutions affiliated with the Ministry of National Education in Turkey, throughout the 2020-2021 academic year. Semi-structured questionnaires were used as data collection tools and descriptive analysis was utilized for the data analysis. The results of the study suggest that teachers consider important to integrate values education with regards to recognizing, understanding and respecting different cultures, along with helping the acquisition of our own national and spiritual values, providing personality/character development and increasing interest in the lesson. It has been observed that the majority of the teachers participating in the research are of the opinion that the activities, content and visuals for values education in the book are not sufficient. Teachers stated that they had difficulties in values education due to reasons such as inadequacy/lack of activity in the textbooks, not being able to receive support from families, the difficulty of internalizing and implementing some values, and the intensity of the curriculum. Teachers also made various suggestions as solutions for these problems.

Keywords: Values, Values Education, English Coursebook, English Teacher.

(The Extended Abstract is at the end of the article)

\section{Giriş}

Eğitimin en temel amaçlarından birinin, iyi bireyler yetiştirmek olduğu bilinen bir gerçektir. Toplum için neyin iyi olduğu konusu, farklı toplumlarda farklı biçimlerde ele alınmakta ve 'iyi' kavramına atfedilenler, toplumun değerleri ölçüsünde değişim göstermektedir. Bu anlamda, eğitimde iyi bireyler yetiştirmekten kasıt genel anlamda toplumun değerlerini benimsemiş bireyler yetiştirmekle eşanlam11 olarak kullanılmaktadır. Nitekim Gelişli’nin (2019) de vurguladığı gibi eğitim aslında, içinde yaşanılan toplumun temel değerlerinin meşrulaştırıldığ 1 kurumlar olmakta ve meşrulaştırılan değerler, eğitim sisteminin öğrencilere kazandırmak istediği amaçlar haline gelmektedir. Bu amaçların kazandırılması sayesinde devletin ve toplumun değerleri bireylere aktarılarak toplumsal kimliğin inşası sağlanabilmektedir. Toplumsal değerler toplumdan topluma değişiklik gösterebilir fakat evrensel değerler temel değerlerdir ve dünyanın her yerinde kabul gören, istenen, aranan, takdir gören bir yapıya sahiptir (Durualp \& Durualp, 2012; Yazıc1, 2013). Bireyler, çevrelerinin toplumsal ve evrensel değerlerinin oluşturduğu bir ortamda şekillenirler. Bu anlamda değerler ve değerlerin aktarımı bireyin ye- 
tişmesinde ve kimlik kazanmasında önemli bir rol oynamaktadır.

Değer tanımının birçok farklı kaynakta farklı şekillerde yapıldığı görülmektedir. En genel anlamıyla değer; "nesne ve olayların bir toplum, bir sınıf ya da bir insan bakımından taşıdığı önemi belirleyen nitelik" şeklinde ifade edilmektedir (Türk Dil Kurumu, 2010). Şişman'a (2002) göre değerler “neyin doğru ve neyin yanlış, neyin iyi ve neyin kötü olduğunu belirlemeye yarayan" ölçütlerdir. Daha geniş anlamda Halstead (1996) değer kavramını "davranışa genel kılavuzluk eden ve karar verme, inanç veya eylemlerin değerlendirilmesinde temel bir nokta olarak kabul edilen; bütünlük ve kimlikle yakından bağlantılı ilkeler, temel inançlar, idealler, standartlar veya yaşam duruşları" olarak tanımlamaktadır (s. 5). Değerleri tutum, eylem, inanç, bilinç, etik, ahlak, ilke, doğru ve yanlış gibi kavramlarla ilişkilendiren Aspin (2000) değerler eğitimini, gençlere değerler hakkında diğer insanlarla ilişki kurma, değerleri ve kuralları akıllıca uygulama yeteneği ile ilgili bilgi verme ve bunu yapmak için yerleşik bir eğilime sahip olmalarını sağlama olarak görmüştür. Ahlaki eğitim veya karakter eğitimi olarak da bilinen değerler eğitimi okullarda, akademik başarıyı güçlendirmek de dâhil olmak üzere, gençlerde olumlu ve etik sosyal davranışların ve yeterliliklerin gelişimini sağlamak için pedagojiler ve bireyi destekleyen yapılar oluşturmaktır (Berkowitz, 2011).

Değerler eğitiminin tohumlarının atıldığı ilk yer ailedir (Ulusoy \& Dilmaç, 2016). Ancak ailenin ardından okullarda da öğrenciye toplum tarafindan benimsenen evrensel ve toplumsal değerlerin aktarımının yapıldığı bilinmektedir (Çengelci ve diğerleri, 2013). Nitekim yapbozdaki eksik kareleri tamamlama görevi, yaşama ve öğrenme ortamı olan okullarındır. Günümüzde toplumların erozyona uğradığı bu dönemde okulun rolü çok daha önemli hale gelmiştir. Okullarda değerler, tüm derslerde farklı yöntem ve tekniklerle, ders dışı etkinliklerle, materyallerle ve ders kitaplarında açık ve örtük bir şekilde verilmektedir. Öğretim programlarına göre ders kitapları en çok tercih edilen materyallerdir. Ancak ders kitapları yalnızca eğitim materyalleri değildir, ayrıca bireysel ve toplumsal bilgi kaynaklarıdır. Ünsal ve Güneş’e (2004) göre ders kitapları öğretim sürecinin vazgeçilmez araçları olan tamamlayıcı öğretim materyalleridir. Ders kitapları, değerlerin kazandırılmasında aktif bir rol oynamaktadır. Ersoy ve Şahin'e (2012) göre de ders kitapları toplumun her kesimine ulaşt1$\breve{g} 1$ için toplum üzerinde çok önemli katkısı vardır. Bu anlamda ders kitapları, yalnızca ilgili dersin konusuna ilişkin bilgiler vermemekte aynı zamanda değerler eğitimini açık ve örtük bir şekilde yansıtmaktadır. Bu nedenle değerler eğitiminin işlevselliğinin tespit edilmesinde ders kitaplarının incelenmesinin 
önemli bir yere sahip olacağını söylemek mümkündür. Alan yazın göz önünde bulundurulduğunda, ders kitaplarının değerler eğitimi bazında incelendiği birçok çalışmanın alan yazında yer aldığı görülmektedir (Karaca \& Uzunkol, 2019; Kırmız1, 2014; Mosleh, 2014; Türkben, 2019). Ancak İngilizce dersleri hem toplumsal hem de evrensel değerlerin bir bağlamiçerisinde verilmesini sağlaması bakımından değerler eğitiminin yapılmasında önemli derslerden biri olmasına rağmen (Raith, 2017; Wu \& Navera, 2018; Zhu, 2011) Türkiye'de İngilizce ders kitaplarına ilişkin yapılan çalışmaların çok az sayıda olduğu tespit edilmiştir. Örneğin Başaranol (2017) ortaöğretim ders kitaplarını temel değerler bakımından gözden geçirmiş, Aslan (2019) ortaokul İngilizce ders kitaplarındaki değerleri incelemiş, Aydın ve Can Aran (2020) ise ortaokul İngilizce ders kitaplarında evrensel değerleri tespit etmeye çalışmıştır. Görüldüğü gibi İngilizce ders kitaplarının değerler eğitimi açısından incelenmesine ilişkin çalışmalar son beş yıl içinde gerçekleştirilmeye başlanmıştır. Bilindiği üzere Milli Eğitim Bakanlığınca okutulan ders kitapları belirli aralıklarla güncellenmektedir. Ortaokul seviyesinde yapılan kitap incelemesi çalışmaları 2018-2019 yılı kitaplarını içermekte ve bütün ortaokul seviyesi kitaplarını gözden geçirmektedir. Ancak bu çalışmada 2020-2021 yılı itibariyle okutulmaya başlanan İngilizce 5. sınıf ders kitabı seçilerek daha derinlemesine inceleme yapılmaya çalışılmış, ayrıca bu sayede yapılmış olan diğer araştırmalar sonucunda elde edilen verilerle karşılaştırma yapılabilmesi mümkün hale gelmiştir. Kitap incelemesi çalışması için özellikle 5. sınıf ders kitaplarının seçilmesinin bir diğer sebebi ortaokul seviyesinin ilk kademesi olan 5. sınıf seviyesinde yer alan öğrencilerin, Piaget'in Bilişsel Gelişim Kuramına göre soyut işlemler döneminin başladığ 1 yaş olan 11 yaş grubunda yer almaları olmuştur. Nitekim bu yaş itibariyle birey; soyut düşünmeye, değer ve inanç sistemini yapılandırmaya ve fikir dünyasıyla aktif olarak ilgilenmeye ve düşüncesini etkinliklerine yansıtmaya başlamaktadır (Senemoğlu, 2013). Bu yaş itibariyle verilecek olan eğitiminde değerler eğitimine yer verilmesinin ve müfredatta ve kitaplarda değerlerin yerinin keşfedilmesinin, öğrencinin bundan sonraki hayatını değerler çerçevesinde yapılandırmasında önemli bir rol oynayabileceği düşünülmektedir. İngilizce Öğretim Programlarında da 2, 3 ve 4. sınıf seviyelerinde öğrencilerin İngilizce dersini sevmelerinin ve İngilizce öğrenimine karşı olumlu tutumlar geliştirmenin hedeflendiği; ancak 5. sınıf seviyesinde yabancı dili gerçek yaşamda kullanmanın hedeflenmeye başlandığ 1 görülmektedir. Dil eğitiminde gerçek yaşamla ilişkilendirmenin ilk olarak 5. sınıf seviyesinde hedeflenmesi ve gerçek yaşamla ilişkilendirmenin sağlanmasında değerlerin yerinin daha etkin bir biçimde kullanılabileceği düşüncesiyle de özellikle İngilizce dersi 5. sınıf ders kitabının incelenmesi çalışma 
için uygun görülmüştür. Ders kitabına ilişkin öğretmen görüşlerinin alınması da araştırmayı yapılan diğer araştırmalardan ayırmaktadır.

Ders kitaplarının yanı sıra öğretmenlerin derslerinde değerler eğitimine verilen yer hakkındaki görüşlerinin belirlenmesinin de, değerler eğitiminin sağlıklı bir biçimde yapılmasında önemli bir yer tutacağı düşünülmektedir. Nitekim öğretmen, sosyal ve ahlaki eğitimin bir parçası olarak yalnızca değerlerin aktarıc1s1 değil aynı zamanda uygulayıcısı konumundadır. Bu nedenle öğretmenlerin kişisel veya özel hayatında, gençlere uygun bir ahlaki örnek olma gerekliliğiyle tutarsız davranışlarda bulunmayan kişiler olmaları hedeflenmektedir (Brady, 2011; Carr \& Landon, 1998). Öğretmenler tarafından uygulanan değerler, öğrencilerin değerleri anlamasını ve uygulamasını etkilemektedir (Mahmood ve diğerleri, 2017). Öğretmenlerin değerler eğitiminin gerekliliği, ders kitaplarında hangi değerlere yer verildiği, hangilerinin eksik kaldığı, değerler eğitimini yaparken zorlandıkları noktalar ve değerler eğitiminin ne şekilde yapılması gerektiğine ilişkin önerilerinin tespit edilmesinin, değerler eğitimi konusunda öğretmenlerin bakış açısının tespit edilmesi ve bu konuda daha bilinçli hale gelmeleri yönüyle önemli olacağını söylemek mümkündür. Nitekim bu araştırma kapsamında, öğretmenlerin ders kitaplarına değerler eğitimi kapsamında incelemeleri ve görüşlerini ifade etmeleri istenmektedir. Bu durum ayrıca öğretmenlerin, öğrencilere değerler aktarımı yapmalarını daha kolay hale getirecek, uzun vadede ise iyi yetişmiş bireylerin topluma kazandırılmasına kapı aralayabilecektir. Bütün bunların yanı sıra, araştırmanın ders kitaplarının incelenmesi ve öğretmen görüşlerinden yola çıkarak verecekleri önerilerin göz önünde bulundurularak değerlendirmeler yapılmasının, değerler eğitimi üzerinde çal1şan program geliştirme alanı uzmanlarına ve araştırmacılara katkı sağlayacağı düşünülmektedir.

Değerler eğitiminde öğretmenin rolünün bir getirisi olarak öğretmen eğitiminde değerler eğitiminin yeri (Hansen, 2008; Maaranen ve diğerleri, 2019, Thornberg, 2008) öğretmen adaylarının değer ve değerler eğitimi hakkındaki görüşleri (Akıtürk \& Kahraman, 2019; Dilmaç, Bozgeyikli \& Çikili, 2008; Sarı, 2005) ve yine öğretmenlerin değer ve değerler eğitimi hakkındaki görüşleri (Batmaz \& Erdoğan, 2019; Bayırlı ve diğerleri, 2020; Uzun \& Köse, 2017) ile farklı derslerde değerler eğitiminin yerine ilişkin görüşlerinin (Balc1 \& Yelken, 2013; Özleşmiş, 2019; Yiğittir \& Öcal, 2011) alındığı çalışmalara alanyazında sıklıkla rastlandığı görülmektedir. Ancak İngilizce öğretmenlerinin değerler eğitimine ilişkin görüşlerinin alındığı çalışma sayısının Türkiye'de 
çok az olduğu görülmektedir. Bu çalışmalardan birinde Baydır (2018) İngilizce öğretmenlerinin 2017 taslak İngilizce öğretim programındaki değerler eğitimi ve uygulamalarına yönelik görüşlerini tespit etmeye çalışmış ve sonuçta öğretmenlerin öğretim programlarında değerler eğitimine daha fazla yer verilmesini olumlu karşıladıklarını, ancak yeni İngilizce öğretim programını değerler eğitimi bakımından birçok yönden yetersiz bulduklarını ifade etmiştir. Öğretim programlarının yanı sıra özel bir sınıfın (5. sınıf) ders kitabının incelenmesiyle İngilizce öğretmenlerinin görüşlerinin tespit edileceği bir çalışmanın, alanyazına daha ayrıntılı bilgiler kazandırması yönüyle katkı sağlayacağı düşünülmektedir. Bütün bu nedenlerle araştırmanın amacı Ortaokul 5.sınıf İngilizce Happy English Ders Kitabının değerler bağlamında analiz edilmesi ve İngilizce öğretmenlerinin 5.sınıf ders kitaplarındaki değerler eğitimiyle ilgili görüşlerinin ortaya konması olarak belirlenmiştir. Bu amaç doğrultusunda aşağıdaki sorulara cevap aranmaktadir:

1. Ortaokul 5.sınıf İngilizce Happy English Ders Kitabında yer alan değerler hangileridir?

2. İngilizce öğretmenlerinin İngilizce eğitiminde değerler eğitiminin gerekliliği hakkındaki görüşleri nelerdir?

3. Öğretmenlerin 5. sınıf ders kitabında değerler eğitimine yönelik yer alan etkinliklerin, içeriklerin ve görsellerin yeterlilik ve etkililik durumu hakkındaki görüşleri nelerdir?

4. Öğretmenler değerler eğitimi kapsamında 5. sınıf İngilizce ders kitabında öncelikle hangi değerlerin verilmesi gerektiğini düşünmektedirler?

5. Öğretmenlerin ders kitabındaki değerlerin öğrencilere kazandırılması noktasında zorlandığı noktalar nelerdir?

\section{Yöntem}

Ortaokul 5. sınıf ders kitabının değerler eğitimi kapsamında incelendiği ve İngilizce öğretmenlerinin değerler eğitimine ilişkin görüşlerinin alındığ 1 bu çalışmada yöntem kısmında araştırma deseni, çalışma grubu, veri toplama araçları, veri toplama süreci ve verilerin analizinden bahsedilmektedir.

\section{Araştırma Deseni}


Araştırmada nitel araştırma yöntemi kullanılmıştır. Bu araştırma yönteminde ele alınacak konu veya konuların herhangi bir müdahale yapılmadan, doğal yapısı bozulmadan değerlendirilmesi söz konusudur. Nitel araştırmalarda istatistiksel analizler kullanılmamaktadır (Jackson, 2009). Desen olarak ise nitel araştırmalarda en sık kullanılan desenlerden biri olan temel nitel araştırma deseninden faydalanılmıştır. Bu desen, nitel araştırma yönteminin tüm özelliklerini taşımakla birlikte aynı zamanda katılımcıların bir konu, durum, süreç, bakış açısı veya dünya görüşü hakkındaki görüşlerini ele alıp incelemeyi de hedeflemektedir. Bu desende genel olarak tümevarımsal analizlerden faydalanılmaktadır (Merriam, 2002). Çalışmada da hem 5. sınıf İngilizce ders kitabının incelenmesinde hem de öğretmenlerle değerler eğitimine ilişkin görüşlerini ortaya koymaya çalışan anket sonuçlarından elde edilen verilerde temel nitel araştırma işe koşulmakta ve tümevarımsal analizlerden faydalanılmaktadır.

\section{Çalışma Grubu}

Araştırmanın çalışma grubu, Milli Eğitim Bakanlığı bünyesinde görev yapan ve 5. sınıf İngilizce derslerine giren İngilizce öğretmenleri arasından seçilmiştir. Araştırmaya katılacak olan öğretmenlerin amaçlı örneklem yöntemlerinden biri olan maksimum çeşitlilik örnekleme yöntemi ile farklı yaş, cinsiyet, kıdem ve illerde görev yapıyor olmasına dikkat edilerek çeşitlilik sağlanmaya çalışılmıştır. Böylelikle olası farklı durumların ve bakış açılarının çalışmaya yansıtılmas1 amaçlanmaktadır. Anketlerden elde edilen veriler süreçte değerlendirilerek katılımcı sayısı 40 ile sınırlandırılmıştır. Araştırmanın çalışma grubuna ilişkin bazı demografik özellikler Tablo 1'de verilmiştir.

\begin{tabular}{|c|c|c|c|}
\hline Kategoriler & & Frekans & Toplam \\
\hline \multirow{7}{*}{ Yaş } & $21-25$ & 10 & \multirow{7}{*}{40} \\
\hline & $26-30$ & 12 & \\
\hline & $31-35$ & 0 & \\
\hline & $36-40$ & 8 & \\
\hline & $41-45$ & 8 & \\
\hline & 46 ve üzeri & 1 & \\
\hline & Belirtilmemiş & 1 & \\
\hline \multirow{2}{*}{ Cinsiyet } & Kadın & 33 & \multirow{2}{*}{40} \\
\hline & Erkek & 7 & \\
\hline
\end{tabular}




\begin{tabular}{|c|c|c|c|}
\hline \multirow{6}{*}{ Kıdem } & $1-5$ y1l & 10 & \multirow{5}{*}{40} \\
\hline & $6-10 \mathrm{yll}$ & 16 & \\
\hline & $11-15$ y1l & 4 & \\
\hline & $16-20 \mathrm{y} 1 \mathrm{l}$ & 3 & \\
\hline & $21-25$ y1l & 1 & \\
\hline & Belirtilmemiş & 6 & \multirow{21}{*}{40} \\
\hline \multirow{20}{*}{ Çalışmakta olduğu il } & Tokat & 7 & \\
\hline & İstanbul & 4 & \\
\hline & Gaziantep & 3 & \\
\hline & Amasya & 3 & \\
\hline & Kayseri & 3 & \\
\hline & Konya & 3 & \\
\hline & Tekirdağ & 2 & \\
\hline & Yalova & 2 & \\
\hline & Afyonkarahisar & 2 & \\
\hline & Rize & 1 & \\
\hline & Kocaeli & 1 & \\
\hline & Erzurum & 1 & \\
\hline & Şanlıurfa & 1 & \\
\hline & Ağn1 & 1 & \\
\hline & Uşak & 1 & \\
\hline & Bolu & 1 & \\
\hline & Van & 1 & \\
\hline & Ankara & 1 & \\
\hline & Ordu & 1 & \\
\hline & Belirtilmemiş & 1 & \\
\hline \multirow{8}{*}{ Ders verilen sinıf seviyeleri } & Anasınıfi & 1 & \\
\hline & 2. $\sin 1 f$ & 8 & \\
\hline & 3. sinif & 9 & \\
\hline & 4. $\sin i f$ & 9 & \\
\hline & 5. $\sin 1 f$ & 40 & \\
\hline & 6. $\sin 1 f$ & 30 & \\
\hline & 7. $\sin i f$ & 27 & \\
\hline & 8. sinif & 22 & \\
\hline
\end{tabular}

Tablo 1'de görüldüğg̈ gibi araştırmanın çalışma grubunu 40 öğretmen oluşturmaktadır. Yaş ile ilgili bulgular incelendiğinde araştırmaya katılanların büyük bir çoğunluğunun 26-30 yaş aralığında olduğu görülmektedir. Çalışmaya 33 kadın, 7 erkek katılmıştır. Öğretmenlerin kıdem süreleri incelendiğinde 6-10 yıl arasında hizmet süresi çalışma grubunun en büyük kısmını oluşturmaktadır. Öğretmenlerin çalışmakta olduğu iller incelendiğinde toplam belirtilen il sayısı 19, belirtilmeyen ise 1 ilden oluştuğu görülmektedir. Öğretmenlerin ders verdiği sınıf seviyeleri incelendiğinde tamamının 5.sınıf seviyesinde derse girdiği görülmektedir. Bunun yanısıra öğretmenlerden bazılarının farklı sınıf seviyele- 
rinde de ders verdiği görülmektedir.

\section{Etik Kurul Onayı}

$\mathrm{Bu}$ çalışmada kullanılan veri toplama araçlarının etik açıdan uygunluğuna Gaziosmanpaşa Üniversitesi Sosyal ve Beşeri Bilimler Araştırmaları Etik Kurulu'ndan 09.04.2021 tarih ve 08.10 numaralı karar ile gerekli izin alınmıştır.

\section{Veri Toplama Araçları}

Bu çalışmada 2020-2021 eğitim-öğretim y1lı itibariyle okutulmaya başlanan İngilizce dersi öğretim programına dayalı olarak yazılan Ortaokul 5.sınıflarda Milli Eğitim Bakanlığı (MEB) tarafından okutulması uygun görülen 'Happy English' İngilizce ders kitabı (Ceylan ve diğerleri, 2019) üniteler bazında incelenerek hangi değerlere ne şekilde yer verildiği irdelenmiştir. Analiz birimi olarak kitapta yer alan görseller ve sözel ifade olarak cümleler baz alınarak değerlendirmeler yapıldı. Ayrıca veri çeşitliliği açısından önemli olduğu ve ilgili alanyazına katk1 sağlayacağı düşünülerek 5.sınıfta ders veren İngilizce öğretmenlerinin değerler eğitimine yönelik görüşleri açık uçlu anket sorularıyla toplanmıştır. Araştırmanın ilk kısmında 5. sınıf ders kitabı ele alınarak doküman analizi yöntemi ile yer verilen değerlere ilişkin analizler yapılmıştır. İkinci k1sım için yarı-yapılandırılmış anket formları aracılığıyla veriler elde edilmiştir. Yarı yapılandırılmış anket formu araştırmacılar tarafından hazırlanmışı̧ı. Form hazırlanırken öncelikle ilgili alan yazın incelenmiştir. Alanyazına dayalı olarak oluşturulan 6 soruluk taslak görüşme formunun kapsam geçerliğini sağlamak üzere üç akademisyen ve bir dil uzmanının görüşleri alınmış, bu görüşler doğrultusunda bazı sorular üzerinde değişiklikler yapılmış ve form yeniden yapılandırılmıştır. Anket formunda öğretmenlere İngilizce eğitiminde değerler eğitiminin gerekliliği, 5. sınıf ders kitabında değerler eğitimine yönelik yer alan etkinliklerin, içeriklerin ve görsellerin yeterlik ve etkililik durumu, 5. sınıf İngilizce ders kitabında öncelikle hangi değerlerin verilmesi gerektiği, yeterince yer verilmediğini düşünülen değerler ve değerlerin kazandırılmasında zorlandıkları noktalar hakkındaki görüşleri ile ilgili sorular yöneltilmiştir. 


\section{Veri Toplama Süreci}

Veri toplama sürecinde öncelikle 5. sınıf ders kitapları alanyazında kitap inceleme çalışmalarında (Bknz. Aslan, 2019; Balcı \& Yelken, 2013; Ersoy \& Şahin, 2012; Karaca \& Uzunkol, 2019) sıklıkla yer alan değerler göz önünde bulundurularak tüm çalışmalarda yer alan ortak değerlerin ortaya çıkarılması, ayrıca araştırmacılar tarafından İngilizce ders kitabında yer alması gerektiği düşünülen değerlerin kapsam içine alınması yoluyla araştırmacılar tarafından bir değerler listesi belirlenmiş; 5. sınıf İngilizce ‘Happy English' ders kitabında hangi değerlerin ne sıklıkta bahsedildiğinin hem sözel hem görsellerde analiz edilmesiyle ders kitabı değerler bakımından incelenmiştir. Çalışmada araştırmacılar tarafından alanyazından faydalanılarak incelenmesi gerekli görülen değerler Tablo 2'de alfabetik sırayla verilmiştir.

\begin{tabular}{ll}
\hline \multicolumn{2}{l}{ Tablo 2: Çalışma kapsamında incelenen değerler listesi } \\
\hline Aile birliğine önem verme & Kutsal mekanlara saygı \\
\hline Arkadaşlık & Kültürel ve sanatsal değerlere önem verme \\
\hline Azzim & Merhamet \\
\hline Başkalarını önemseme & Özbakım \\
\hline Birlikte ve barış içinde yaşama & Özdenetim \\
\hline Çalışkanlık & Özgüven \\
\hline Devlete, millete ve bayrağa hassasiyet & Paylaşım \\
\hline $\begin{array}{l}\text { Diğer ülkelerin değerleri, gelenekleri, tarihi hakkında } \\
\text { bilgi sahibi olma }\end{array}$ & Sağlıklı yaşam \\
\hline Dil farklılıklarına saygı & Sanata ve sanatçya verilen önem \\
\hline Doğa sevgisi & Saygı \\
\hline Empati & Sorumluluk \\
\hline Farklılıklara saygı gösterme & Sporseverlik \\
\hline Hayvan sevgisi & Sevgi \\
\hline Hoşgörü & Toplumsal kurallara uyma \\
\hline Huzur & Vatanseverlik \\
\hline Kendi ülkesinin değerlerini, geleneklerini, tarihini & Yardımseverlik \\
bilme & \\
\hline Kibar olma & \\
\hline
\end{tabular}

Araştırmanın ikinci bölümünde öğretmenlere, yarı-yapılandırılmış anket formları e-posta aracıllğıyla gönderilmiş, öğretmenlerin ders kitabında var olan değerleri incelemeleri ve anket formunda yer alan sorulara yanıt vermeleri istenmiştir. Öğretmenlere ulaştırılan anket formunda " $\mathrm{Bu}$ anket formu ile sizlerin 5. sınıf İngilizce ders kitaplarında yer alan değerler hakkındaki görüşleriniz açığa çıkarılmaya çalışılacaktır. Lütfen soruları yanıtlamadan önce formu ve ders kitabını gözden geçiriniz.” şeklinde bir açılama yapılarak Öğretmenlerin anket sorularına bakarak kitapta incelemeleri gereken kısımları fark etmeleri ve bu 
noktalara dikkat ederek kitabı incelemeleri, ardından anket formunda yer alan soruları yanıtlamaları istenmiştir. Ayrıca görüşlerini ifade eden katılımcıların ifade ettikleri bilgilerin tümünün gizli tutulacağ araştırma kapsamı dışında hiçbir şekilde kullanılmayacağı belirtilerek öğretmenlerden "Çalışmaya katılmayı kabul ediyorum" kutucuğunu işaretlemeleri talep edilmiş, yalnızca gönüllü olan öğretmenlerden veriler toplanmıştır.

\section{Verilerin Analizi}

Veriler, betimsel analiz yöntemi ile analiz edilmiştir. Betimsel analiz yönteminde veriler araştırma sorularının ortaya koyduğu temalara göre düzenlenebileceği gibi, görüşme sürecinde yer alan sorular dikkate alınarak da sunulabilir. $\mathrm{Bu}$ analiz yönteminin temel amac1, elde edilen bulguların okuyucuya özetlenmiş ve yorumlanmış bir şekilde sunulmasını sağlamaktır (Yıldırım \& Şimşek, 2013). Çalışmada, nitel analiz sonuçlarının geçerlik ve güvenirliğini artırmak için çeşitli yöntemler kullanılmıştır. Analizlerde sıklıkla doğrudan alıntılara yer verilerek ayrıntılı betimlemelere yer verilmesi, zaman kisitlaması yapılmadan derinlik odaklı veri toplanması, anket sorularının kapsam geçerliğinin sağlanması amacıyla uzman görüşüne başvurulması ve araştırmacı tarafından yapılan kodlamaların danışman tarafından sürekli kontrol edilerek düzeltilmesi ile tutarlık incelemesinin yapılması geçerliği ve güvenirliği sağlamaya yönelik önlemleri oluşturmaktadır. Ayrıca tutarlık katsayısının belirlenmesinde Miles ve Huberman'in (1994) 'Güvenirlik Düzeyi= Katılma / Katılma + Katılmama' formülü kullanılmıştır. Uzlaşılan kod sayısı 39’dur. Üzerinde uzlaşma sağlanamayan kod sayısı ise 9 olarak belirlenmiştir. Bu nedenle güvenirlik katsayısı 39 / $39+9=0.81$ şeklinde tespit edilmiştir.

Etik izin: Tokat Gaziosmanpaşa Üniversitesi Sosyal ve Beşeri Bilimler Araştırmaları Etik Kurulunun 09.04.2021 tarih 08. Oturumda almış olduğu karar neticesinde çalışmanın uygulanmasının etik açıdan bir sorun teşkil etmediği görülmüştür.

\section{Bulgular}

Araştırmanın bulguları 5. sınıf ders kitabında yer alan değerlere ilişkin bulgular ve öğretmenlerin değerler eğitimine ilişkin görüşlerine yönelik bulgular başl1kları altında değerlendirilmiştir. Öğretmenlerin değerler eğitimine ilişkin görüşlerine yönelik bulgular ise temalara uygun olarak İngilizce dersinde değerler eğitiminin gerekliliğine ilişkin görüşler, değerler eğitimine yönelik etkinlik, 
içerik ve görsellerin yeterlilik durumuna ilişkin görüşler, İngilizce derslerinde öncelikle verilmesi gerektiği düşünülen değerler, İngilizce öğretmenlerinin değerler eğitimi yaparken zorlandıkları noktalar, öğretmenlerin değerler eğitiminin verilmesine ilişkin önerileri şeklinde sıralanmıştır.

\section{Sınıf Ders Kitabında Yer Alan Değerlere İlişkin Bulgular}

5.sınıf İngilizce ders kitabında Merhaba (Hello), Benim şehrim (My town), Oyunlar ve hobiler (Games and Hobbies ), Benim rutinim (My Daily routine), Sağlik (Health), Filmler (Movies), Parti zamanı (Party Time), Zindelik (Fitness), Hayvan barınağ (The Animal Shelter) ve Bayramlar (Festivals) üniteleri yer almaktadır. Grafik 1'de 5. sınıf İngilizce ders kitabının tüm ünitelerinde yer alan değerler gösterilmiştir.

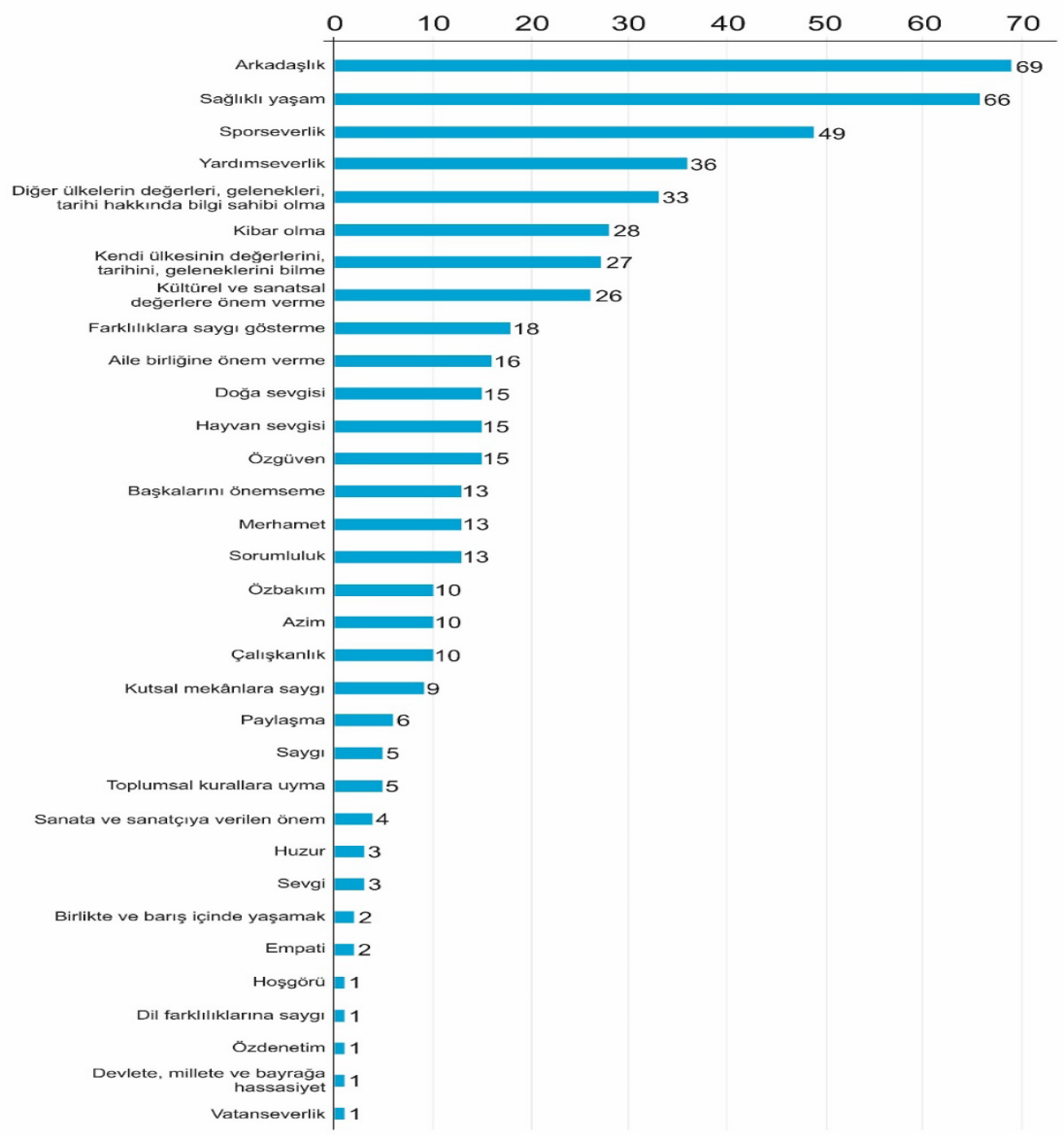


Grafik 1: 5.Sınıf İngilizce Ders Kitabının Ünitelerinde Yer Alan Değerler

Kitaptaki tüm üniteler incelendiğinde kitapta yer alan değerlerin sıklıkları sırasıyla arkadaşlık (\%13.19), sağlıklı yaşam (\%12.61), sporseverlik (\%9.36), yardımseverlik (\%6.88), diğer ülkelerin değerleri, gelenekleri, tarihi hakkında bilgi sahibi olma (\%6.30), nezaket (\%5.35), kendi ülkesinin değerlerini, tarihini, geleneklerini bilme (\%5.16), kültürel, sanatsal değerlere önem verme (\%4.97), farklılıklara saygı gösterme (\%3.44), aile birliğine önem verme (\%3.05), doğay1 sevme (\%2.86), hayvan sevgisi (\%2.86), özgüven (\%2.86), başkalarını önemseme (\%2.48), merhamet (\%2.48), sorumluluk (\%2.48), öz-bakım (\%2.10), azim (\%1.91), çalışkanlık (\%1.91), kutsal mekanlara saygı (\%1.72), paylaşma (\%1.14), sayg1 (\%0.95), toplumsal ve hukuki kurallara uyma (\%0.95), sanata ve sanatçıya verilen önem $(\% 0.76)$, huzur (\%0.57), sevgi $(\% 0.57)$, birlikte ve barış içinde yaşama (\%0.38), empati (\%0.38), hoşgörü (\%0.19), dil farklılığına sayg1 (\%0.19), özdenetim (\%0.19), devlete, millete ve bayrağa hassasiyet $(\% 0.19)$ ve vatanseverlik (\%0.19) olduğu tespit edilmiştir. Grafikten anlaşıldığ 1 üzere ders kitabında yer alan değerlerin \%25'ini arkadaşlık ve sağlıklı yaşam değerleri kapsamaktadır. En düşük frekansa sahip olan değerlerin ise hoşgörü, dil farklılıklarına saygı, özdenetim, devlete, millete ve bayrağa hassasiyet ve vatanseverlik olduğu görülmektedir. Aşağıdaki tabloda bahsedilen değerlere ilişkin örnek görseller ve sözel ifadeler yer almaktadır:

Tablo 3: Değerlere İlişkin Görsel ve Sözel İfade Örnekleri
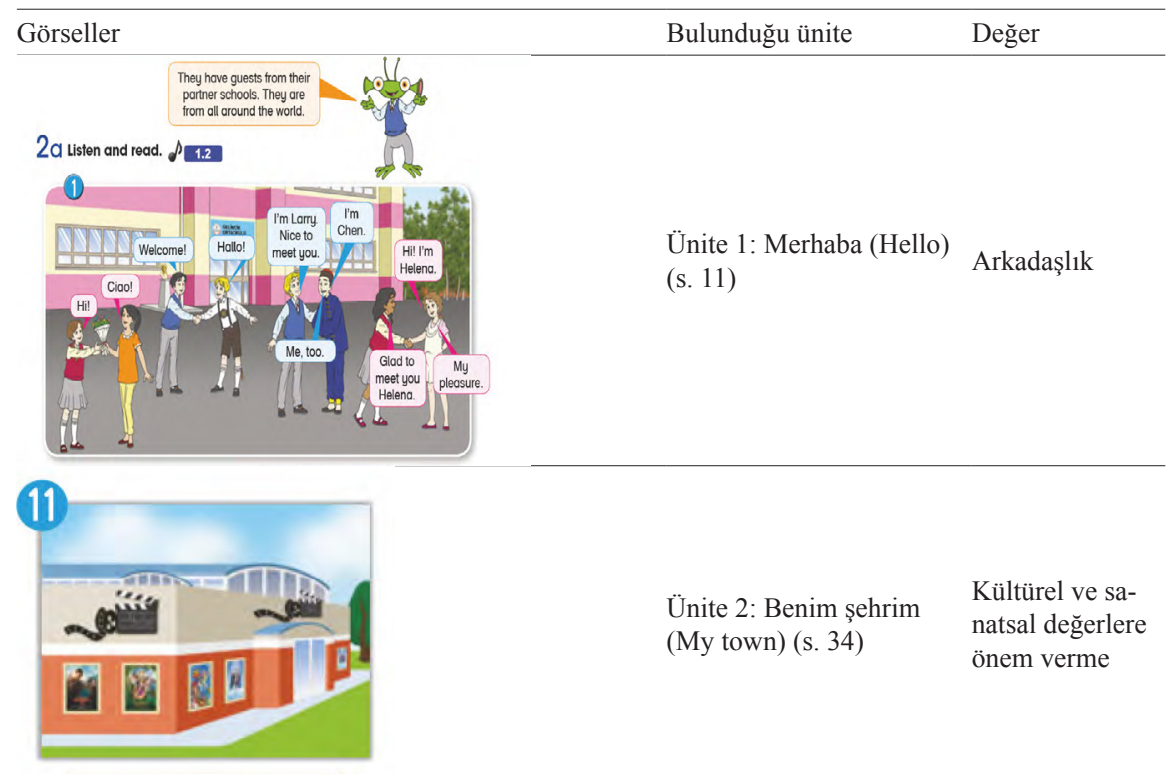

Kültürel ve sa-

Ünite 2: Benim şehrim natsal değerlere (My town) (s. 34) önem verme 


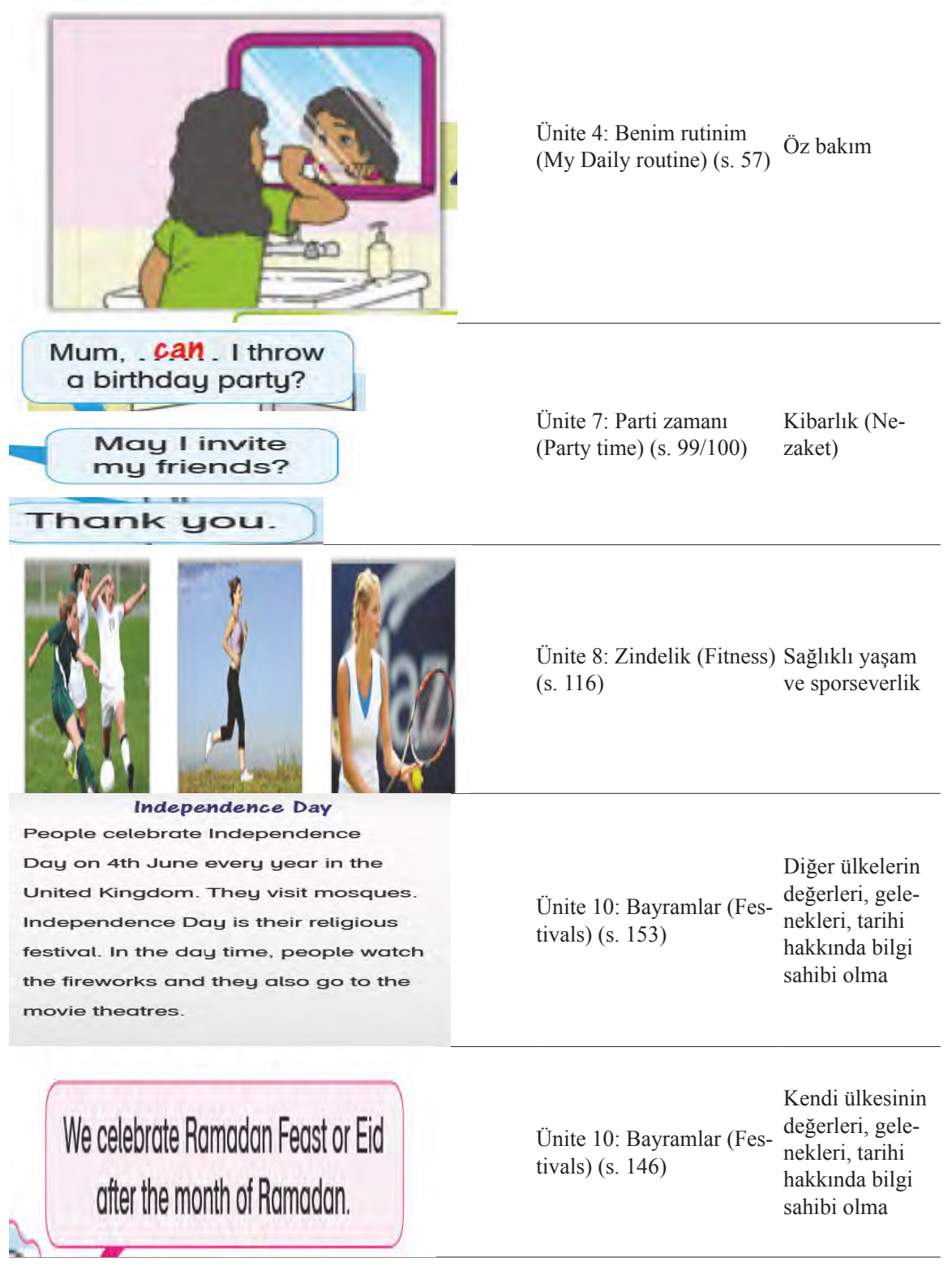

\section{Öğretmenlerin Değerler Eğitimine İlişkin Görüşlerine Yönelik Bulgular}

Araştırmanın ikinci bölümünde öğretmenlerin İngilizce derslerinde değerler eğitimine ilişkin görüşleri tespit edilmeye çalışılmıştır. Bu başlık altında İngilizce öğretmenlerinin İngilizce dersinde değerler eğitiminin gerekliliği, 5. Sınıf 
seviyesinde değerler eğitimine yönelik etkinlik, içerik ve görsellerin yeterlilik durumu, öncelikle verilmesi gerektiği düşünülen değerler hakkındaki görüşleri ile değerler eğitimi yaparken zorlandıkları noktalar ve değerler eğitiminin verilmesinde önerilerine yer verilmiştir.

\section{İngilizce dersinde değerler eğitiminin gerekliliğine ilişkin görüşler}

İlk olarak öğretmenlere İngilizce derslerinde değerler eğitimini gerekli bulup bulmadıkları sorulmuştur. Verilen yanıtlar doğrultusunda Tablo 4'te verilmiş olan tema ve kodlar elde edilmiştir.

Tablo 4: İngilizce Dersinde Değerler Eğitiminin Gerekliliği

\begin{tabular}{lll}
\hline Tema & Kod & Frekans \\
\hline & Farklı kültürleri tanıma, anlama ve saygı & 11 \\
\cline { 2 - 3 } & Kendi milli ve manevi değerlerimizi kazanmayı sağlama & 6 \\
\cline { 2 - 3 } Kişilik/karakter gelişimi sağlama & 6 \\
\cline { 2 - 3 } $\begin{array}{l}\text { İngilizce dersinde } \\
\text { değerler eğitiminin } \\
\text { gerekliliği }\end{array}$ & Derse karşı ilgiyi artırma & 6 \\
\cline { 2 - 3 } & Değerlerin içselleştirilmesini/davranışa dönmesini sağlama & 5 \\
\cline { 2 - 3 } & Değerlerin evrenselliğini anlamayı kolaylaştırma & 3 \\
\cline { 2 - 3 } & Yeni değerlerin yeni bir dille öğretiminin etkililiği & 3 \\
\cline { 2 - 3 } & Değerlere göre yaşama gerekliliği & 3 \\
\cline { 2 - 3 } & İnsanlara model olma & 3 \\
\cline { 2 - 3 } & Suç oranlarını azaltma & 1 \\
\cline { 2 - 3 } & Olumlu tutum ve davranışlar kazandırma & 1 \\
\cline { 2 - 3 } & Gerekli görmüyorum & 3 \\
\hline
\end{tabular}

Tablo 4’te görüldüğü gibi öğretmenlerin büyük bir kısmı farklı kültürleri tan1ma, anlama ve bu kültürlere saygı duyma açısından değerler eğitiminin gerekli olduğunu belirtmiştir. Yine değerler eğitiminin kendi milli ve manevi değerlerimizin kazandırılmasında da önemli bir yer tuttuğu, bu nedenle gerekli olduğu görüşü öğretmenler tarafından ifade edilmiştir. Ayrıca öğretmenler, değerler eğitiminin kişilik ve karakter gelişimini sağlaması ve derse karşı ilgiyi artırmas1 yönleriyle de önemli ve gerekli olduğunu belirtmektedirler. Bu kodlamalara ilişkin öğretmenlerin kendi ifadeleri aşağıdaki şekildedir:

Dil kendimizi ifade etmek için kullandığımız bir araç. Yeni bir dili değerlerle birlikte tanımak ve öğrenmenin o dile olan bakış açımızı da etkileyeceği bir gerçektir. Ayrıca değerler eğitiminin o dili kullanma biçimimizi de etkilemesi beklenen bir durumdur. Bu nedenle İngilizce eğitiminde değerler eğitiminin de bir rolü olması gerektiğini düşünüyorum. (K3, kadın, 23)

Değerler eğitimi tartışılamaz bir öneme sahiptir. İngilizce eğitiminde değer- 
ler eğitiminin özellikle farklı kültürleri tanıma ve farklılıklara saygı açısından önemli olduğunu düşünüyorum. (K19, K, 26)

Hedef dil ediniminde evrensel olan kavramların göz ardı edilmesi duyguları olmayan bir robota dil yazılımı yüklemekten öteye gidememektir. Öz benliğini kaybetmek üzere olan bir nesle ilgi duyduğu alanda kazandırılmak istenen erdem kolaylıkla verilebilir. (K27, kadın, 30)

Gelişim dönemindeki çocuklarda toplumsal değerlerin kazandırılması oldukça önemlidir. Değerler eğitiminin çocuğun kişilik gelişimi üzerinde olumlu etkileri olacaktır. (K10, kadın, 37)

Öğretmenler, değerler eğitiminin öğrencilerin derse karşı ilgilerini de olumlu yönde etkileyebileceğini düşünmektedirler. Ayrıca öğretmenler, değerlerin içselleştirilmesinde ve davranışa dönmesinin sağlanmasında, toplumun huzuru, mutluluğu ve gelişiminde, değerlerin evrenselliğinin anlaşılmasının kolaylaşmasında da İngilizce dersinde değerler eğitiminin yeri olduğunu düşünmektedirler. Bunun yanı sıra öğretmenler, yeni değerlerin yeni bir dille öğretiminin daha etkili sonuçlar doğuracağını düşünmektedirler. Bütün bunların yanı sıra öğretmenlere göre değerlere göre yaşamanın gerekliliği, öğrencilerin insanlara model olmasının gerekliliği, değerler eğitiminin suç oranlarını azaltması ve öğrencilere olumlu tutum ve davranışlar kazandırması yönüyle de gerekli görülmektedir. Yalnızca bir öğretmen İngilizce derslerinde değerler eğitimini gerekli görmediğini “İngilizce eğitiminde değerler eğitimini gerekli görmüyorum, çünkü İngilizce dili bizim anadilimiz olmadığı için bizim kültürümüzle bağdaştırılarak öğretilecek bir dil değil zaten.” (K39, kadın, 28) şeklindeki ifadeleriyle dile getirmiştir. Bu kodlamalara ilişkin öğretmen görüşleri aşağıdaki şekildedir:

İngilizce derslerinde kendi kültüründen öğeler gören çocuğun dil öğrenimini karşı ilgisi artacaktır. İngilizceye bakış açısı değişen çocuk hedef kültürün değerlerini de öğrenmek isteyecektir. (K24, kadın, 23)

İngilizce eğitimi de, dünyada yaşayan bütün insanların benzer değerlere sahip olmasını sağlayacak, daha yaşanılabilir bir dünya oluşturulması açısından bireylere dünyanın geri kalanını tanıma, anlama ve işbirliği yapma firsatı verecektir. (K38, erkek, 51)

Bana göre İngilizce dersi sadece anlamsız konuların bir araya geldiği bir ders değil, dil öğretirken öğrencilerin farklı temalarda bilgilendiği ve bilinçlendiği bir derstir. Öğrencilere değerler eğitimi İngilizce dersinde kolaylıkla temaların içine yedirilmiş bir şekilde verilebilir diye düşünüyorum.” (K6, kadın, 28) 
Değerler eğitimine yönelik etkinlik, içerik ve görsellerin yeterlilik durumuna ilişkin görüşler

İngilizce öğretmenlerinin değerler eğitimine yönelik etkinlik, içerik ve görsellerin yeterlilik durumuna ilişkin görüşlerinin analizi sonucunda elde edilen tema ve temaya ilişkin kodlar Tablo 5'te gösterilmiştir.

Tablo 5: Değerler Eğitimine Yönelik Etkinlik, İçerik ve Görsellerin Yeterlilik Durumu

\begin{tabular}{cll}
\hline Tema & Kod & Frekans \\
\hline \multirow{3}{*}{ Değerlerin yeterlilik durumu } & Yeterli değil & 32 \\
\cline { 2 - 3 } & Yeterli & 7 \\
\cline { 2 - 3 } & Kararsız & 1 \\
\hline
\end{tabular}

Tablo 5'te görüldüğü gibi İngilizce öğretmenlerinin büyük çoğunluğunun $(n=32)$ görüssleri değerler eğitimine yönelik etkinlik, içerik ve görsellerin yeterli olmadığı yönündedir. Değerler eğitimine ilişkin etkinlik, içerik ve görsellerin yeterli olduğunu düşünen 7 öğretmen bulunurken 1 öğretmenin de bu konuda kararsız kaldığ ifadeleri aşağıdaki şekildedir:

5. sınıf ders kitaplarının değerler eğitimine yönelik etkinlikler açısından zengin olmadığını, yetersiz kaldığını düşünüyorum. Ayrıca görsel kullanımı açısından ciddi bir eksiklik olduğu benim görüşüm. (K3, kadın, 23)

5. sınıf kitabını hem ders içi etkinlikler adına hem de değerler eğitimi ile ilgili yetersiz buluyorum. Çocuklara farklı temalarda kelimeler ve dil bilgisi konuları bir arada sunuluyor, ancak değerler eğitimi konusunda Happy English kitabında iki ünitenin az da olsa değindiğinden bahsedebiliriz. The Animal Shelter ünitesinde kitap bize destek materyal sunmasa da biz öğrencilerle bu üniteyi işlerken hayvanları korumanın öneminden bahsederiz. Çevremizdeki hayvanlar için bizler neler yapabiliriz, bu konularda çözümler üretmeye çalışırız. Festivals ünitesinde ise farklı kültürleri öğrenirken, farklılıkların bizim zenginliğimiz olduğunu, her kültürden ve ülkeden insana saygılı davranmamız gerektiğini konuşuruz. (K6, kadın, 28)

5.sınıf ders kitabında yer alan içerikler değerler eğitimi yönünden yeterli durumdadır. (K40, erkek, 37)

\section{İngilizce derslerinde öncelikle verilmesi gerektiği düşünülen değerler}

Araştırma kapsamında öğretmenlere İngilizce derslerinde öncelikle yer verilmesi gerektiği düşünülen değerlerin neler olması gerektiği de sorulmuştur. Öğ- 
retmenlerin bu soruya ilişkin görüşlerinin analizi sonucunda elde edilen tema ve temaya ilişkin kodlar Tablo 6'da gösterilmiştir.

\begin{tabular}{|c|c|c|}
\hline Tema & Kod & Frekans \\
\hline \multirow{19}{*}{$\begin{array}{l}\text { Öncelikle verilmesi } \\
\text { gerektiği düşünülen } \\
\text { değerler }\end{array}$} & Sayg1/özsayg1 & 21 \\
\hline & Yardımseverlik ve paylaşım & 17 \\
\hline & Sevgi (aile, çevre, hayvan vb.) & 15 \\
\hline & Doğruluk/dürüstlük & 13 \\
\hline & Sorumluluk & 12 \\
\hline & Hoşgörü ve barışseverlik & 11 \\
\hline & Milli değerlere sahip çıkma & 10 \\
\hline & Arkadaşlık & 7 \\
\hline & Güzel ahlak ve nezaket kuralları & 7 \\
\hline & Empati & 6 \\
\hline & Güven/özgüven & 5 \\
\hline & Bencillikten uzaklık/cömertlik & 5 \\
\hline & Çevre bilinci ve duyarlılık & 5 \\
\hline & Adalet & 4 \\
\hline & Sağlıklı yaşama ve temizlik & 4 \\
\hline & Sabır & 3 \\
\hline & İsraf etmeme/tutumluluk & 2 \\
\hline & Dini değerler & 2 \\
\hline & Çalışkanlık & 2 \\
\hline
\end{tabular}

Tablo 6'da görüldüğü gibi araştırmaya katılan İngilizce öğretmenleri tarafından İngilizce derslerinde yer alması gerektiği düşünülen 20 farklı değerin belirtildiği görülmektedir. Öğretmenlerin büyük bir çoğunluğunun sayg1 değerine öncelik verdiği görülmektedir. Frekansın en yüksek olduğu saygı/özsayg1 değerini sırasıyla yardımseverlik ve paylaşım, sevgi, doğruluk ve dürüstlük, sorumluluk, hoşgörü ve barışseverlik, milli değerlere sahip çıkma, arkadaşlık, güzel ahlak ve nezaket kuralları, empati, güven/özgüven, bencillikten uzaklık/ cömertlik, çevre bilinci ve duyarlılık değerleri takip etmektedir. Az sayıda da olsa adalet, sağlıklı yaşama ve temizlik, sabır, israf etmeme/tutumluluk, dini değerler ve çalışkanlık gibi değerlerin de İngilizce derslerinde yer alması gerektiğini düşünen öğretmenler bulunmaktadır. Öğretmenlerin görüşlerini yansıtan ifadeler aşağıda verilmiştir.

Farklılıklara saygı duymak, özgüven duygularının gelişmesi, yardımlaşma konusunda daha çok içerik olması gerektiğini düşünüyorum. Çünkü çocuklar kendilerine oldukça yabancı olan ve farklı gelen bir dil hakkında önyargılı yaklaşabiliyorlar. Ayrıca yardımlaşmanın önemini kavradıklarında bunu ders ortamına da taşıyıp sınıfta oynadıkları takım oyunlarıyla daha etkili ve eğlenceli bir 
öğrenme sağlayabilirler. Özgüven ise öğrencilerin sınıfta hata yapma korkusu duymadan öğrenmelerine, sınıfta daha aktif olarak kendilerini geliştirme imkanı sağlar. Dil öğrenimi elbette ki hatasız olmaz öğrencilere hata yapmanın öğrenmeye dahil olan bir süreç olduğunu hissettirmeliyiz. (K7, kadın, 24)

Değerler eğitiminde 5.sınıfla da hoşgörü ve saygının temelinin sağlamlaştırılması gerektiğini düşünüyorum. Çünkü bir çocukta bu iki ahlaki değer güçlüyse üzerine diğerlerini inşa etmek daha kolay olacaktır. ( K20, kadın, 33)

\section{İngilizce öğretmenlerinin değerler eğitimi yaparken zorlandık- ları noktalar}

İngilizce öğretmenlerinin değerlerin eğitimi yapılırken zorlanılan noktalara ilişkin görüşlerinin analizi sonucunda elde edilen tema ve kodlar Tablo 7'de gösterilmiştir.

Tablo 7: Değer Eğitimi Yapılırken Zorlanılan Noktalar

\begin{tabular}{|c|c|c|}
\hline Tema & Kod & Frekans \\
\hline \multirow{14}{*}{$\begin{array}{l}\text { Değer eğitimi yapılırken } \\
\text { zorlanılan noktalar }\end{array}$} & Sikıntı yaşamıyorum. & 12 \\
\hline & Sikıntı yaşıyorum. & 28 \\
\hline & *Ders kitaplarının yetersizliği/etkinlik eksikliği & 5 \\
\hline & *Ailelerden destek alamama & 4 \\
\hline & $\begin{array}{l}\text { *Değerlerin öğrenciler tarafından ilk kez } \\
\text { duyulmuş olması }\end{array}$ & 3 \\
\hline & $\begin{array}{l}\text { *Farklı kültürlerin aktarımında zorluk } \\
\text { yaşanması }\end{array}$ & 3 \\
\hline & $\begin{array}{l}\text { *Bazı değerlerin içselleştirilmesinin ve } \\
\text { uygulanmasinın zor olması }\end{array}$ & 3 \\
\hline & $\begin{array}{l}\text { *Kültürel farklılıklara hitap etme konusunda } \\
\text { yaşanan zorluklar }\end{array}$ & 3 \\
\hline & *Müfredat yoğunluğu & 3 \\
\hline & $\begin{array}{l}\text { *Değerlerin bağlam içerisine yerleştirilmemiş } \\
\text { olması }\end{array}$ & 2 \\
\hline & *Gerçekçi diyalogların eksikliği & 2 \\
\hline & *Öğrenciler arası farklılıklar olması & 1 \\
\hline & * Değerleri somutlaştırmanın zorluğu & 1 \\
\hline & *Uzaktan eğitim sebebiyle yaşanan sıkıntılar & 1 \\
\hline
\end{tabular}

Tablo 7'de görüldüğü gibi öğretmenlerin çoğunluğunun $(n=28)$ değerlerin öğrencilere kazandırılmasında sıkıntı yaşadığı görülmektedir. Öğretmenlerin, değerlerin öğrencilere kazandırılmasında zorlandığı noktalardan ilkini ders kitaplarının etkinlik yönünden eksikliği oluşturmaktadır. Bu durum, daha önce yöneltilmiş olan etkinlik, içerik ve görsellerin yeterlilik durumuna ilişkin öğretmenlerin çoğunluğunun kitapların yeterli olmadığı görüşüyle paralellik göstermektedir. Bu konuya ilişkin K9 ders kitapları yeterli olmadığı için eksiklikleri 
kendisinin kapatma girişimlerini "Ders kitapları genellikle kazanımları tamamen karşılamadığından öğretmen olarak gördüğüm eksikleri, projeler, hikaye okuma veya grup etkinlikleri ile kapatmaya çalışıyorum. Ancak burada öğretmenden öğretmene farklılık olacağından eğitimde bütünlük olmamaktadır." (K9, kadın, 39) ifadeleriyle dile getirmiştir. Bir diğer öğretmen de "Evet, değerlere yönelik etkinliklerin az oluşu öğrenciye o değeri bir ders gibi vermemizin önüne geçiyor. Öğretmen bu değerlere önem verince ders dışı konuşmuş gibi algılanabiliyor. Müfredatın içinde olmalı değerler eğitimi, kelimeler ve dilbilgisi kuralları o konu çerçevesinde öğretilmeye çalışılmalı." (K23, kadın, 27) ifadelerini kullanarak değerlere yönelik etkinliklerin az olduğundan ve değerlerin bağlam içinde öğretilmesi gerekliliğinden bahsetmiştir. Kitaplarda gerçekçi diyalogların eksikliği de öğretmenlerin değerler eğitimi yaparken zorlanmalarına sebep olmaktadır. Öğretmenlerden birinin incelemeleri sonucunda belirttiği görüşler aşağıdaki şekildedir:

5.sınıf ders kitabında 2. üniteyi incelediğimde yön bilgisi sadece bir harita ya da kroki kullanılarak anlatılmıştır. Karşıdan karşıya geçmeye çalışan bir yaşlıya yardım eden öğrenciler gösterilerek hem yön bilgisi hem binalar anlatılabilirdi. Bunun yanı sıra görme ya da yürüme engelli bireylerin şehirde yaşadığı zorluklar ve onlara yardımcı olan öğrenciler tasvir edilerek çocuklarımızın nezaket ve yaşlılara, engelli bireylere saygı gibi değerler kazanmaları sağlanabilirdi. Her insanın bir engelli adayı olduğu unutulmamalı, onlara günlük hayatımızda nasıl yardımc1 olunabileceği küçük yaşta kazandırılması gereken bir değerdir. (K30, kadın, 37)

Değerler eğitimi konusunda ailelerden destek alamama, değerlerin öğrenciler tarafından ilk kez okulda duyulmuş olması da yaşanan sıkıntılar arasında dile getirilmiştir. Konuya ilişkin K2'nin kendi ifadeleri "Değerlerin ilk kez duyulması kazanım açısından zor olabiliyor.” (K2, erkek, 30) şeklindedir.

Farklı kültürlerin aktarımında zorluk yaşanması ve kültürel farklılıklara hitap etme konusunda yaşanan zorluklar da öğretmen tarafindan dile getirilen sıkıntılar arasında yer almıştır. Bu durumu K12 "Kendi kültürümüzde yer almayan yani yabancı olduğumuz değerlerden bahsederken zorlandığımız yerler olabiliyor.” (K12, kadın, 25) ifadeleriyle dile getirmiştir. Ayrıca bazı değerlerin içselleştirilmesinin ve uygulanmasının zor olması, müfredat yoğunluğu nedeniyle değerlere yeterince yer verilememesi, öğrenciler arası farklılıklar olması, değerleri somutlaştırmanın zorluğu da belirtilen sıkıntılar arasında yer almıştır. Bir öğretmen son zamanlarda pandemi nedeniyle uzaktan eğitim faaliyetleri 
yürüttüklerini ve bu durumun değerler eğitimin yapılmasında zorluklara sebep olduğunu ifade etmiştir.

\section{Öğretmenlerin değerler eğitiminin verilmesine ilişkin önerileri}

Araştırma süreci boyunca, araştırma soruları dâhilinde olmasa da, araştırmaya katılan İngilizce öğretmenlerinin değerler eğitiminin verilmesi konusunda bazı önerileri olmuştur. İngilizce öğretmenlerinin konu ile ilgili önerileri sonucunda elde edilen bulgular Tablo 8'de gösterilmiştir.

\begin{tabular}{|c|c|c|}
\hline Tema & Kod & Frekans \\
\hline \multirow{10}{*}{$\begin{array}{l}\text { Değerler eğitimi- } \\
\text { nin verilmesinde } \\
\text { öneriler }\end{array}$} & Ailelerle iletişim halinde olmak/destek almak & 6 \\
\hline & $\begin{array}{l}\text { Ek etkinlikler sağlayacak materyal geliştirilmesi (hikaye, film, role } \\
\text { play aktiviteleri vb.) }\end{array}$ & 4 \\
\hline & $\begin{array}{l}\text { Sosyal sorumluluk projelerine katılım (hayvan barınakları, huzurevi } \\
\text { ziyaretleri, yardım kampanyalarına katılım vb.) }\end{array}$ & 3 \\
\hline & Kendi kültürümüze yer verme & 3 \\
\hline & Kitapların değerler eğitimi bakımından daha nitelikli hale getirilmesi & 2 \\
\hline & Müfredatlarda daha fazla değerler eğitimine yer verme & 2 \\
\hline & Hedef dilin kültürüne yer verme & 2 \\
\hline & Değerler eğitimi panosu altında proje ödevleri & 2 \\
\hline & İşbirlikçi çalışmalara daha sık yer verilmesi & 2 \\
\hline & Eğlenerek öğrenmenin sağlanması & 1 \\
\hline
\end{tabular}

Tablo 8'e göre araştırmaya katılan öğretmenlerin değerler eğitiminin verilmesine yönelik önerileri incelendiğinde en yüksek frekansa sahip olan önerinin ailelerle iletişim halinde olmak/destek almak olduğu görülmektedir. Bu konuya ilişkin K35'in görüşleri aşağıdaki şekildedir:

Değerler başlı başına anlatılması, kazandırılması zor bir alan... Özellikle velilerle de desteklenmezse. Çalıştığım okulda öğrencilere ben ne kadar saygılı olmayı, sorumluluk değeri çerçevesinde yaşadığımız alanı temiz tutmak gerektiğini de anlatsam hatta bunu gün içinde kazandırdığımı da düşünsem; öğrenci eve gidince annesine saygı duyulmayan ya da etrafa çöp atmanın normal karşılandığı hatta ve hatta yaşadıkları alanda çöp konteynırının bile olmadığı bir ortama geri döndüğünde benim neredeyse kazandırdığım tüm değerler yok olup gidiyor. Her ne öğretmek olursa olsun eğitim gerçekten aile-öğrenci-öğretmenden oluşan üçayaklı masaya benzer. Bir ayağının eksik olması masayı nasıl yıkıyorsa eğitimde de bahsettiklerimden biri eksik olsun tüm öğrenilenler her şey yıkılıyor ve tekrar sil baştan başlamak zorunda kalınılıyor. Kısacası değerler eğitimini kazandırmaya çalışırken en çok zorlandığım nokta velilerden geri dönüt alamamak. (K35, kadın, 25) 
Bunun dışında öğretmenler, ek etkinlikler sağlayacak materyal geliştirilmesi, kitapların değerler eğitimi bakımından daha nitelikli hale getirilmesi, müfredatlarda daha fazla değerler eğitimine yer verme, değerler eğitimi panosu altında proje ödevleri yapılması gibi önerilerle öğretim sürecinde değerlerin müfredata, kitaplara ve etkinliklere entegre edilmesi gerekliliğinden bahsetmişlerdir. Öğretmenlerden birinin "Ders kitabının içinde olmasa da seçmeli derslerimizde kaynak bulmakta zorlanıyoruz. Bakanlığımız seçmeli derslere dönük küçük hikayeler ve dinleme metinleri veya role playpack hazırlarsa biz de zevkle kullanırız. (K9, kadın, 39) ifadeleri bu görüşü yansıtır niteliktedir. Bir diğer öğretmen ise kitap konusunda serzenişte bulunmuş ve görüşlerini " $\mathrm{Bu}$ gidişle ben bir kitap yazacağım çünkü bu kitaplardan çok muzdaripiz.” (K16, erkek, 35) şeklinde ifade etmiştir. Müfredatlarda daha fazla değerler eğitimine yer verilmesi gerektiğini düşünen öğretmenlerden birinin görüşleri ise aşağıdaki şekildedir:

Neslimizin ve çağımızın en büyük problemi maalesef değer yoksunluğu diyebilirim. Küçüğünü büyüğünü bilmeden sadece sanal aleme gömülerek yetişen nesilleri izleyerek üzülüyoruz ama biz de sanal alem noktasında onlardan çok farksız değiliz. Umarım okullarda ve hatta aileden başlamak üzere değerler eğitiminin üzerine düşüleceği bir program hazırlanır ülkemiz adına. Yoksa gelecek adına çok da ümitli olamayacağım üzülerek. (K33, kadın, 27)

Belirtilen bu öneriler dışında, hayvan barınakları, huzurevi ziyaretleri, yardım kampanyaları gibi sosyal sorumluluk projelerine katılım, ders kapsamında kendi kültürümüze yer verme ve bunun yanında hedef dilin kültürüne de yer verme, işbirlikçi çalışmalara daha sık yer verilmesi ve eğlenerek öğrenmenin sağlanmasının gerekliliği de öneriler arasında dile getirilmiştir. Öğretmenlerin bu konulara ilişkin önerilerini yansıtan ifadelerden bazıları aşağıda verilmiştir.

Bir İngilizce öğretmeni olarak İngilizce öğretiminde kendi değerlerimiz ve kültürümüzün de kesinlikle yer alması gerektiğini düşünüyorum. Öğrenciler elbette öğrendiği dilin insanlarının değerleri hakkında bilgi edinmeli fakat dil öğretiminde sadece hedef dilin kültürünün öğretilmesini doğru bulmuyorum. Ders kitaplarında partiler, festivaller, cadılar bayramı gibi etkinliklerin yanı sıra bizim milli ve dini bayramlarımıza ve aynı şekilde toplumumuza özgü diğer değerlere de aynı ölçüde ağırlık verilirse öğrencilerin de hedef dili daha çok benimseyeceğini ve dile daha çok ilgi duyacağını düşünüyorum. Sonuçta hiçbirimiz normal hayatımızda sürekli festivallere ve bayramlara gitmiyoruz. Bu yüzden gerçek yani günlük hayatımıza ağırlık verilmesi gerektiğini düşünüyorum. (K12, kadın, 25)

Zaten yetişen bireyler bizim kültürümüzde, bizim değerlerimizle yetişiyor. He- 
def dil ne ise, hedef dile ait değerler fikir olması açısından tanıtılmalı. (K26, kadin, 27)

\section{Tartışma, Sonuç ve Öneriler}

Bu çalışmada ilk olarak 2019 yılına ait İngilizce öğretim programına dayalı olarak Ortaokul 5.sinıflarda MEB tarafından okutulması uygun görülen 'Happy English' ders kitabı üniteler bazında incelenmiş ve hangi değerlere ne şekilde yer verildiği irdelenmiştir. Ayrıca araştırma sonuçları 1şığında 5.sınıfta ders veren İngilizce öğretmenlerinin, İngilizce dersindeki değerler eğitimi hakkındaki görüşleri ve 5.sınıf ders kitaplarında yer alan değerlerin yeterlilik durumları hakkındaki düşünceleri, açık uçlu anket sorularının değerlendirilmesi ile ortaya çıkarılmıştır.

Öğretmenlerin 5. sınıf İngilizce dersinde değerler eğitimi hakkındaki görüşlerinin alındığı kısımda yalnızca bir öğretmen İngilizce dersinde değerler eğitimine gerek görmediğini belirtmiş, diğerleri farklı sebeplerle değerler eğitiminin İngilizce dersinde de yer alması gerektiğini belirtmişlerdir. Bu sebeplerden en sı bahsedilenler; kültürleri tanıma, anlama ve bu kültürlere saygı duyma açısından değerler eğitiminin gerekli olması ve aynı zamanda öğrencinin kendi milli ve manevi değerlerinin kazandırılmasında önemli bir yer tutması şeklinde ifade edilmiştir. Şu an uygulamada bulunan MEB İngilizce Öğretim Programlarında (2018) da belirli evrensel ve toplumsal değerlerin bireyler ve toplumlar için öneminden bahsedilmekte ve bu programlar aracılığıyla bu değerlerin öğretimine daha fazla önem verildiği belirtilmektedir. Alanyazında da İngilizce öğretimi ile kültür ve değerlerin aktarımı konusunda sıkı bir bağ olduğu fark11 çalışmalarda vurgulanmaktadır (Chinh, 2013; Cruz, 2010; Sudartini, 2012). Örneğin bu çalışmalardan birinde Izadpanah (2011) İngilizce öğretmenlerinin kültür kavramını daha çok değerler ve inançlarla bağdaştırdıklarını ve kültürel bilgileri dersleriyle birleştirme konusunda olumlu tutumlara sahip olduklarını tespit etmiştir. Bu yönüyle söz konusu çalışmanın alanyazına benzer sonuçlar verdiği ve dünya çapında da öğretmenlerin, İngilizce öğretiminde kültür ve değerlerin aktarımı konusuna önem verdiğini göstermektedir.

Kişilik ve karakter gelişimini sağlaması, öğretmenlerin değerler eğitiminin gerekliliği için önemli gördükleri bir diğer noktayı oluşturmaktadır. Değerler eğitiminin öğrencilerin karakter gelişimleri üzerinde etkisi olduğundan birçok farklı çalışmada da bahsedilmektedir (Freakley, 2006; Livo, 2003; S1lay, 2013). Ayrıca öğretmenler derse karşı ilgiyi artırmasında, değerlerin içselleştirilme- 
sinde ve davranışa dönmesinin sağlanmasında, toplumun huzuru, mutluluğu ve gelişiminde ve değerlerin evrenselliğinin anlaşılmasının kolaylaşmasında da İngilizce dersinde değerler eğitiminin yeri olduğunu düşünmektedirler. De Jamenson ve De Güell (2013) de benzer şekilde öğrencilerin İngilizce derslerinde hedef kültüre ilişkin değerlerle karşılaştıkça farklılıkların ve heterojenliğin mantığını ve anlamını anlayıp takdir etme olasılıklarının artacağından bahsetmiştir. Yeni değerlerin yeni bir dille öğretiminin daha etkili sonuçlar doğuracağı, değerlerle yaşamanın gerekliliği, öğrencilerin insanlara model olmasının gerekliliği, değerler eğitiminin suç oranlarını azaltması ve öğrencilere olumlu tutum ve davranışlar kazandırması da öğretmenler tarafından sıralanan sebepler arasındadır. Dil derslerinin öğretim programlarıyla bütünleştirilebileceğini ve bu sayede öğrencilerin değerler yönüyle topluma kazandırılabileceğini ifade eden çalışmalara alanyazında da rastlandığı görülmektedir (Başaranol, 2017; Ratih, 2017; Zhu, 2011). Bütün bu bulgular, İngilizce dersinde değerler eğitiminin ne denli önemli olduğunu ve bu öneme binaen programlarda yer alan değerlerin öğretimine önem verilmesi gerektiğini gözler önüne sermektedir.

Ceylan, Gümüş ve Kabukçu (2019) tarafından yazılmış olan ve 2020-2021 eğitim-öğretim yılı müfredatında okutulan 5. sınıf İngilizce ders kitabı değerler eğitimi bakımından incelendiğinde kitapta toplam 33 değerin yer aldığı tespit edilmiştir. Bu değerler sırasıyla arkadaşlık, sağliklı yaşam, sporseverlik, yardımseverlik, diğer ülkelerin değerleri, gelenekleri, tarihi hakkında bilgi sahibi olma, nezaket, kendi ülkesinin değerlerini, tarihini, geleneklerini bilme, kültürel ve sanatsal değerlere önem verme, farklılıklara saygı gösterme, aile birliğine önem verme, doğa sevgisi, hayvan sevgisi, özgüven, başkalarını önemseme, merhamet, sorumluluk, öz-bakım, azim, çalışkanlık, kutsal mekanlara saygı, paylaşma, saygı, toplumsal kurallara uyma, sanata ve sanatçıya verilen önem, huzur, sevgi, birlikte ve barış içinde yaşama, empati, hoşgörü, dil farklılıklarına sayg1, özdenetim, devlete, millete ve bayrağa hassasiyet, vatanseverlik şeklindedir. Aslan (2019) benzer bir yaklaşımla 2018 yılında Yalçın, Genç, Orhon ve Şahin (2018) tarafından yazılmış olan ve 2018-2019 eğitim-öğretim yılı müfredatında okutulan 5. sınıf ders kitabını incelemiş ve kitapta; sorumluluk, sporseverlik, sağlıklı olmaya önem verme, farkl1lıklara saygı, doğa sevgisi, okuma sevgisi, nezaket, arkadaş sevgisi, aile birliğine önem verme, müzikseverlik, temizlik gibi değerlerin sıklıkla yer aldığını ifade etmiştir. Ayrıca aile içi işbirliğine, milli değerlere, aile büyüklerine, dini değerlere önem verme, estetik duyarlılık, misafirperverlik, yardımseverlik, bayrak sevgisi, okul sevgisi, paylaşma, Atatürk sevgisi, dürüstlük, kardeş sevgisi, sanatseverlik ve tarihsel mira- 
sa duyarlılık gibi değerlere de yer verildiğini tespit etmiştir. Aydın ve Can Aran (2020) tarafından gerçekleştirilen çalışmada da incelenen evrensel değerlerin ders kitaplarında yer verilme oranının \%20'nin altında olduğu tespit edilmiştir. Her üç çalışmanın bulguları da kitaplarda benzer değerlere yer verildiğini ancak bu değerlerin kitapta yer alma sıklıklarının farklılık arz ettiğini göstermektedir.

Çalı̧̧ma kapsamında değerlendirilen bu kitapta en çok arkadaşl1k, sağlıklı yaşam ve sporseverlik değerlerine; en az ise empati, hoşgörü, dil farklılıklarına sayg1, özdenetim, devlete, millete ve bayrağa hassasiyet ve vatanseverlik değerlerine yer verildiği tespit edilmiştir. 2018 MEB İngilizce öğretim programında yer alan değerlerin arkadaşlık, adalet, dürüstlük, özdenetim, sabır, saygı, sevgi, sorumluluk, vatanseverlik ve fedakârlık olduğu göz önünde bulundurulduğunda incelenen bu kitapta değerlerden, arkadaşlık ve sorumluluk değerine yeterli oranda yer verilmesine karşın sevgi, saygı, sabır, özdenetim ve vatanseverlik değerlerine ilişkin nispeten daha az veriye rastlanmaktadır. Çalışmanın bulguları içerisinde de öğretmenlerin büyük bir çoğunluğunun saygı değerine öncelik verdiği görülmektedir. Frekansın en yüksek olduğu sayg1/özsayg1 değerinin yanı sıra öğretim programlarında yer bulan fakat kitapta nispeten daha az sayıda bulunan sevgi, hoşgörü ve barışseverlik, milli değerlere sahip çıkma, empati gibi değerlere de yer verilmesi öğretmenler tarafından dile getirilmiştir. Ayrıca öğretmenler ders kitaplarında yardımseverlik ve paylaşım, doğruluk ve dürüstlük, sorumluluk, arkadaşlık, güzel ahlak ve nezaket kuralları, güven/özgüven, bencillikten uzaklık/cömertlik, çevre bilinci ve duyarlılık gibi değerlere daha sık yer verilmesi gerektiğini düşünmektedirler. Ders kitabının incelenmesi, daha önce yapılmış olan kitap incelemesi çalışmalarının bulguları (Aslan, 2019; Aydın \& Can Aran, 2020) ve öğretmenlerin görüşleri doğrultusunda elde edilen bütün bu bulgularda yola çıkarak, İngilizce ders kitabının İngilizce Öğretim Programının ruhunu tam olarak yansıtmadığını söylemek mümkündür. Nitekim çalışmaya katılan İngilizce öğretmenlerinin büyük çoğunluğu da İngilizce ders kitaplarındaki değerler eğitimine yönelik etkinlik, içerik ve görsellerin yeterli olmadığını düşünmektedir. Bu nedenle İngilizce öğretim programının öğrencilere kazandırmayı hedeflediği bilgi ve becerilerin yanı sıra değerler eğitiminin de göz ardı edilmeden ders kitaplarında dengeli bir şekilde dağıtılması gerektiğini söylemek mümkündür. Ayrıca dil öğretiminin içerik öğretime entegre edilerek yapılmasını ve dil öğretiminin yanı sıra içeriğe de dikkat edilmesini öneren (Marsh \& Frigols Martin, 2012; Yalçı, 2013) içerik temelli yabancı dil öğretim modelinin İngilizce ders müfredatları ve ders kitapların- 
da değerler eğitimi bağlamında değerlendirilmesinin de bu derslerde değerler eğitiminin kolaylıkla verilebilmesi açısından önemli olacağını söylemek mümkündür. Nitekim çalışmaya katılan öğretmenler de değerler eğitimi yaparken zorlandıkları noktaları açıklarken değerlerin bağlam içerisine yerleştirilmemiş olmasının sıkıntılar yaşamalarına sebep olduğunu belirtmişlerdir. Alanyazında içerik temelli öğretim modelinin değerler eğitimi bağlamında değerlendirildiği çalışmaya rastlanmamış olmakla beraber dil eğitiminin içerikle birleştirilmesinin öğrencilerin dil becerilerinde (okuma, yazma, dinleme, konuşma) ve başarısında etkili olduğunu gösteren birçok çalışma bulunmaktadır (Dalton-Puffer, 2011;.Lasagabaster, 2008; Ruiz de Zarobe, 2008). Ancak öğretmen ve öğrencilerin dil yeterliliklerinin içerik temelli öğretim programının uygulanmasında zorluklara neden olabildiği de belirtilmektedir (Arnó-Macià \& Mancho-Barés, 2015). Bu bağlamda İngilizce derslerinin içerik temelli öğretim modeli ile birleştirilmesine ilişkin öğretmenlerin bilgilendirilerek ve hem öğretmen hem de öğrencilerin dil yeterlikleri geliştirilerek bu öğretim modeline dayalı öğretimin yapılandırılması ve değerler eğitiminin de bu içeriğe dahil edilmesinin hem dil öğretimi hem de değerlerin aktarımı konusunda öğrencilere yardımcı olabileceğini söylemek mümkündür.

Öğretmenlerin çoğunluğunun değerlerin öğrencilere kazandırılmasında sıkıntı yaşadığı görülmektedir. Değerlerin öğrencilere kazandırılmasında zorlandığ 1 noktalardan ilkinin ders kitaplarının etkinlik yönünden eksikliği oluşturmaktadır. Bu durum, daha önce yöneltilmiş olan etkinlik, içerik ve görsellerin yeterlilik durumuna ilişkin öğretmenlerin çoğunluğunun yeterli olmadığg görüşüyle paralellik göstermektedir. Müfredat yoğunluğu nedeniyle değerlere yeterince yer verilememesi de belirtilen diğer bir sorundur. Farklı çalışmalarda da farklı alan ve derslerde yaşanan müfredat yoğunlukları nedeniyle değerler eğitimine istenilen düzeyde yer verilemediğini belirten çalışmalara rastlanmaktadır (Cice \& Özgan, 2017; Polat ve diğerleri, 2019; Sağlam, 2016). Bu bağlamda ünitelerde konu yoğunluğunun azaltılması ya da ünitelerde konu içeriklerinin çeşitli değerleri barındıran etkinliklerle verilmesinin değerler eğitiminin sağlıklı bir biçimde yürütülebilmesinde önem arz edebileceği söylenebilir. Ayrıca öğretmenlerin çalı̧̧ma kapsamında vermiş olduğu değerler eğitimi bağlamında ek etkinlikler sağlayacak materyal geliştirilmesi, kitapların değerler eğitimi bak1mından daha nitelikli hale getirilmesi, müfredatlarda daha fazla değerler eğitimine yer verilmesi, değerler eğitimi panosu altında proje ödevleri yapılması gibi önerilerin göz önüne alınarak öğretim sürecinde değerlerin müfredata, kitaplara 
ve etkinliklere entegre edilmesi sağlanabilir. Yine öğretmenlerin önerileri arasında yer alan hayvan barınakları, huzurevi ziyaretleri, yardım kampanyaları gibi sosyal sorumluluk projeleri, işbirlikli çalışmalar ve eğlenerek öğrenmeyi sağlayacak etkinliklerle öğrencilerin değerleri yaparak yaşayarak öğrenmeleri sağlanabilir.

Değerler eğitimi konusunda ailelerden destek alamama ve değerlerin öğrenciler tarafından ilk kez okulda duyulmuş olması gibi nedenler de yaşanan sıkıntılar arasında dile getirilmiştir. Öğretmenler, ailede değerler eğitimine ilişkin bir çaba yoksa okulda verilen eğitimin yeterli olamayacağını belirtmektedirler. Ayrıca öğretmenlerin önerileri arasında en yüksek frekansa sahip önerinin de değerler eğitiminin sağlıklı bir biçimde yapılabilmesinde ailelerle iletişim halinde olmak/ destek almak olduğu görülmektedir. Bir diğer deyişle öğretmenler, değerler eğitiminin öğretmen-veli-öğrenci üçgeninde yapıldığında başarılı olabileceğine inanmaktadır. Cice ve Özgan (2017) da değerler eğitimi çalışmalarının verimli bir biçimde yürütülememesinin nedenleri arasında aile ilgisizliğinin olduğunu belirtmişlerdir. Yine Uzun ve Köse (2017) çalışmalarında değerler eğitimi konusunda ailelerin ne denli önemli olduğunu belirterek ailelere değerler eğitimi konusunda bilgilendirme ve bilinçlendirme için toplantılar düzenlenmesi gerektiğini belirtmişlerdir. Bu bulgulardan yola çıkılarak değerlerin öğretiminde aile eğitimine de ayrıca yer verilmesi gerektiğini söylemek mümkündür.

Öğretmenler tarafından belirtilen diğer sıkıntılar arasında farklı kültürlerin aktarımında zorluk yaşanması ve kültürel farklılıklara hitap etme konusunda yaşanan zorluklar da yer almıştır. Bu nedenle öğretmenler, ders kapsamında hem kendi kültürümüze hem de hedef dilin kültürüne de yer verilmesi önerisinde bulunmuşlardır. Sudartini (2012) de çalışmasında, yabancı bir dilin öğretiminin o kültürün öğretimi olmadan yapılmasının mümkün olmadığından ancak bu durumun öğrencilerin kültür karmaşası yaşamalarına neden olabileceğinden bahsetmiştir. Kültürler arası etkileşimin kolaylaşması ve yaygınlaşması ile birlikte kültürler arası iletişim (cross-cultural and intercultural communication) konusuna da sıklıkla değinilmeye başlanmış (Gudykunst, 2003) ve dil eğitiminde kültürler arası iletişim daha fazla dillendirilmeye başlanmıştır (Gökmen, 2005; Kızılaslan, 2010; Saygılı ve Kana, 2018). Elbette ki kültürler arası iletişim, kültürle birlikte değerlerin aktarımını da içermektedir. Kültürlerin ve değerlerin aktarımında herhangi bir dayatma olmaksızın kendiliğinden gerçekleşen etkileşimin kültürel yapıyı olumsuz etkilemeyeceği (Mahiroğulları, 2005) görüşünden yola çıkılarak dil eğitiminde de farklı kültürlerin ve evrensel de- 
ğerlerin eğitiminin yapılmasının, ülkenin kendi kültürünü ve kendine ait değerleri olumsuz yönde etkilemeyeceğini söylemek mümkündür. Ancak çalışmada öğretmenlerin de değindiği gibi dil öğretimi yapılırken hem öğrencilerin kendi kültür ve değerlerine hem de farklı kültür ve değerlere ilişkin bilgiler edinmelerinin sağlanmasının, kültür karmaşasının da önüne geçebileceğini ifade etmek mümkündür.

Bazı değerlerin somutlaştırılmasının, içselleştirilmesinin ve uygulanmasının zor olması öğretmenlerin değerlerin öğretiminde zorluk yaşamalarına sebep olan bir diğer noktayı oluşturmaktadır. Yine öğretmenlere göre öğrenciler arası farklılıklar olması da belirtilen sıkıntılar arasında yer almıştır. Bu anlamda öğretmenlerin hem kendi kültür ve değerlerinin hem de hedef kültür ve değerlerin farkında olmalarının yanı sıra bu değerlerin aktarımı konusunda hangi yaş grubuna hangi değerlerin nasıl öğretilmesi gerektiği gibi konularda da bilgi sahibi olmaları gerekmektedir. Bu nedenle öğretmen adaylarına hizmet öncesi derslerde, öğretmenlere ise hizmet içi kurslarla, değerler ve değerler eğitimi hakkında verilecek bilgilendirmelerin önemli olacağını söylemek mümkündür. Bir öğretmen son zamanlarda pandemi nedeniyle uzaktan eğitim faaliyetleri yürüttüklerini ve bu durumun değerler eğitimin yapılmasında zorluklara sebep olduğunu ifade etmiştir. Covid-19 pandemi sürecinin eğitim üzerine etkilerden bahseden birçok çalışmanın alanyazında yer almaya başladığı görülmektedir (Bozkurt, 2020; Bektaş-Bedir \& Bedir, 2021; Can, 2020; Daniel, 2020; Mishra ve diğerleri, 2020; Sarı \& Nayır, 2020). Ancak özel olarak pandemi süreci ve değerler eğitimi ile ilgili yapılan bir çalışmaya alan yazında henüz rastlanmamıştır. $\mathrm{Bu}$ konu üzerinde yapılacak çalışmaların pandemi sürecinde değerler eğitimi hakkında bilgi sahibi olunması açısından önem arz edeceği düşünülmektedir.

\section{Kaynakça}

Akıtürk, H. K., ve Kahraman, P. B. (2019). Okul öncesi öğretmen adaylarının değerler eğitimine yönelik görüşleri. Değerler Eğitimi Dergisi, 17(38), 267-294.

Arnó-Macià, E., \& Mancho-Barés, G. (2015). The role of content and language in content and language integrated learning (CLIL) at university: Challenges and implications for ESP. English for specific Purposes, 37, 63-73.

Aslan, H. İ. (2019). Ortaokul İngilizce ders kitaplarındaki değerler. (Yayımlanmamış Yüksek Lisans Tezi). Sakarya, Sakarya Üniversitesi.

Aspin, D. (2000). A clarification of some key terms in values discussions. In Moral education and pluralism: Education, culture and values, (M. Leices- 
ter, C. Modgil, S. Modgil eds.) (pp. 171-180) Farmer Press.

Aydın, A. Z., ve Can Aran, Ö. (2020). Ortaokul İngilizce ders kitaplarında evrensel değerlerin incelenmesi. Dil Eğitimi ve Araştırmaları Dergisi, 6(2), 733-751.

Balcı, A., ve Yelken, T. (2013). İlköğretim sosyal bilgiler programında yer alan değerler ve değer eğitimi uygulamaları konusunda öğretmen görüşleri. Ahi Evran Üniversitesi Kırşehir Eğitim Fakültesi Dergisi, 14(1), 195-213.

Başaranol, V. (2017). Ortaöğretim İngilizce ders kitaplarının temel değerler açısından incelenmesi. (Yayımlanmamış Yüksek Lisans Tezi) Bolu: Abant İzzet Baysal Üniversitesi.

Batmaz, O., ve Erdoğan, T. (2019). Sınıf öğretmenlerinin değerler eğitimine yönelik görüşleri. Kastamonu Eğitim Dergisi, 27(6), 2681-2692.

Baydır, E. (2018). Ingilizce ögretmenlerinin 2017 taslak Ingilizce programında yer alan değerler ĕ̆itimi ve uygulamalarına yönelik görüşleri. (Yayımlanmamış Yüksek Lisans Tezi) Eskişehir: Eskişehir Osmangazi Üniversitesi.

Bayırlı, H., Doruk, O., ve Tüfekci, A. (2020). Öğretmenlerin değerler eğitimi hakkındaki görüşleri: Afyonkarahisar örneği. Eğitimde Nitel Araştırmalar Dergisi, 8(3), 865-894.

Bozkurt, A. (2020). Koronavirüs (Covid-19) pandemi süreci ve pandemi sonras1 dünyada eğitime yönelik değerlendirmeler: Yeni normal ve yeni eğitim paradigması. Açıköğretim Uygulamaları ve Araştırmaları Dergisi, 6(3), 112-142.

Bektaş-Bedir, S., ve Bedir, G. (2021). Metaphoric perceptions of teacher candidates about COVID-19. International Journal of Educational Study and Policy, 2(1), 25-39.

Berkowitz, M. W. (2011). What works in values education. International Journal of Educational Research, 50(3), 153-158.

Brady, L. (2011). Teacher values and relationship: factors in values education. Australian Journal of Teacher Education, 36(2), 56-66.

Can, E. (2020). Coronavirüs (Covid-19) pandemisi ve pedagojik yansımaları: Türkiye'de açık ve uzaktan eğitim uygulamaları. Açıkögretim Uygulamaları ve Araştırmaları Dergisi, 6(2), 11-53.

Carr, D., \& Landon, J. (1998). Teachers and schools as agencies of values education: reflections on teachers' perceptions, Journal of Beliefs and Values, 19(2,) 165-176.

Ceylan, C., Gümüş, G., ve Kabukçu, G. (2019). Ortaokul ve Imam Hatip Ortaokulu happy English 5 ders kitabı. Başaran Yayıncılık.

Chinh, N. D. (2013). Cultural diversity in English language teaching: Learners' voices. English Language Teaching, 6(4), 1-7. 
Cice, Y., ve Özgan, H. (2017). Değerler eğitimi uygulamalarının değerlendirilmesi ve geliştirilmesine ilişkin okul çalışma ekibinin görüşleri. Ekev Akademi Dergisi, 21(70), 101-120.

Cruz, J. H. (2010). The role of literature and culture in English language teaching. Linguistica Aplicada, 17, 1-16.

Çengelci, T., Hanc1, B., ve Karaduman, H. (2013). Okul ortamında değerler eğitimi konusunda öğretmen ve öğrenci görüşleri. Değerler Eğitimi Dergisi, 11(25), 33-56.

Daniel, J. (2020). Education and the COVID-19 pandemic. Prospects, 49(1), 91-96.

Dalton-Puffer, C. (2011). Content-and-language integrated learning: From practice to principles?. Annual Review of applied linguistics, 31, 182-204.

De Jamenson, M. M. A., \& De Güell, A. D. (2013). Integrating culture into the EFL lesson. In Actualización en la enseñanza del inglés (A. Leceta and R. I. Cuneo eds.) (pp. 65-69) Universidad Nacional de San Juan.

Dilmaç, B., Bozgeyikli, H., ve Çikili, Y. (2008). Öğretmen adaylarının değer algılarının farklı değişkenler açısından incelenmesi. Değerler Ĕgitimi Dergisi, 6(16), 69-91.

Durualp, E., ve Durualp, E. (2012). İlköğretim II. kademede öğrenim gören öğrencilerin evrensel değerlere ilişkin tutumlarının incelenmesi. Kuramsal Eğitimbilim Dergisi, 5(4), 484-499.

Ersoy, F., ve Şahin, T. (2012). Sosyal Bilgiler ders kitaplarının değerler eğitimi yaklaşımları açısından incelenmesi. Kuram ve Uygulamada Eğitim Bilimleri Dergisi, 12(2), 1535-1558.

Freakley, M. (2006). Values education and character development. Society and the Environment: Teaching SOSE, (Z. Zajda ed.) (pp. 173-184) James Nickolas Publishers.

Gelişli, Y. (2019). Eğitim, öğrenme ve değerlendirme sürecinde etik ilkeler. Eğitimde ahlak ve etik içinde. (B. Oral, A. Çoban ve M. Bars eds.). Pegem Yayıncılık.

Gökmen, E. (2005). Yabancı dil öğretiminde kültürlerarası iletişimsel edinç. Dil Dergisi, (128), 69-77.

Gudykunst, W. B. (2003). Cross-cultural and intercultural communication. Thousand Oaks, Sage Publications.

Halstead, J. M. (1996). Values and values education in schools. In Values in education and education in values (J. M. Halstead and M. J. Taylor eds.) (pp 3-14). Falmer Press, Taylor \& Francis, Inc.

Hansen, D. T. (2008). Values and purpose in teacher education. In Handbook of research on teacher education: Enduring questions in changing contexts, (M. Cochran-Smith, S. Feiman-Nemser, D.J. McIntyre and K. E. Demers eds.) 
(pp. 10-26). Routledge.

Izadpanah, S. (2011). The review study: The place of culture in English language teaching. US-China Foreign Language, 9(2), 109-116.

Jackson, S. L. (2009). Research methods and statistics: A critical thinking approach ( $3^{\text {th }}$ ed.) USA: Wadsworth, Cangage Learning.

Karaca, D., ve Uzunkol, E. (2019). İlkokul matematik ders kitaplarının içerdiği değerler bakımından incelenmesi. Uluslararası Alan Eğitimi Dergisi, 5(2), 55-71.

Kırmızı, F. S. (2014). 4. sınıf Türkçe ders kitabı metinlerinde yer alan değerler. Değerler Ĕ̈itimi Dergisi, 12(27), 217-259.

Kızılaslan, İ. (2010). Yabancı dil öğretmen yetiştirme sürecinde kültürlerarasılık. Milli Eğitim Dergisi, 40(185), 81-89.

Lasagabaster, D. (2008). Foreign language competence in content and language integrated courses. The Open Applied Linguistics Journal, 1(1), 31-42.

Livo, N. J. (2003). Bringing out their best: Values education and character development through traditional tales. Libraries Unlimited.

Maaranen, K., Kynäslahti, H., Byman, R., Jyrhämä, R., \& Sintonen, S. (2019). Teacher education matters: Finnish teacher educators' concerns, beliefs, and values. European Journal of Teacher Education, 42(2), 211-227.

Mahiroğulları, A. (2005). Küreselleşmenin kültürel değerler üzerine etkisi. Journal of Social Policy Conferences. (50), 1275-1288.

Mahmood, M., Rizvi, S. A., \& Perveen, U. (2017). Value related practices used by teacher educators at a public university, Islamabad. Journal of Education and Educational Development, 4(2), 301-320.

Marsh, D., \& Frigols Martín, M. J. (2012). Content and language integrated learning. In The encyclopedia of applied linguistics. C. Chapelle (ed.) Blackwell, pp. 911-20.

Merriam, S. B. (2002). Qualitative research in practice: Examples for discussion and analysis. San Francisco: John Wiley \& Sons, Inc.

Milli Eğitim Bakanlığı (MEB). (2018). Íngilizce dersi öğretim programı (İlkokul ve ortaokul 2, 3, 4, 5, 6, 7 ve 8. sınıflar). Milli Eğitim Bakanlığı.

Miles, M. B. Ve Huberman, A. M. (1994). Qualitative data analysis: An expanded sourcebook. Sage.

Mishra, L., Gupta, T., \& Shree, A. (2020). Online teaching-learning in higher education during lockdown period of COVID-19 pandemic. International Journal of Educational Research Open, 1, 100012.

Mosleh, E. J. I. (2014). Value-based content analysis of 'English for palestine' 8th 
grade course book and suggested value enrichment material. Gaza: The Islamic University of Gaza

Özleşmiş, N. (2019). İlkokul Hayat Bilgisi Dersi kapsamındaki değerler eğitimi uygulamalarına iliş̧kin öğretmen görüşlerinin incelenmesi, (Yayımlanmamış Doktora Tezi) İstanbul: Marmara Üniversitesi.

Polat, B., Kaya, İ. F., ve Yalçınkaya, E. (2019). The problems and solution proposals of social studies teachers in value education. Uluslararası Medeniyet Çalı̧̧maları Dergisi, 4(2), 266-285.

Ratih, I. A. M. (2017). The analysis of classroom character education in English lessons based on the 2013 curriculum. Journal of Psychology and Instruction, 1(2), 97-105.

Ruiz de Zarobe, Y. (2008). CLIL and foreign language learning: A longitudinal study in the Basque Country. International CLIL Research Journal, 1(1), 60-73.

Sağlam, A. (2016). Değerler eğitiminin öğrenci davranışlarına etkisinin veli görüşlerine göre incelenmesi. Türkiye Sosyal Araşttrmalar Dergisi, 20(3), 723-742.

Sarı, E. (2005). Öğretmen adaylarının değer tercihleri: Giresun Eğitim Fakültesi örneği. Değerler Ĕ̆itimi Dergisi, 3(10), 75-90.

Sarı, T., ve Nayır, F. (2020). Pandemi dönemi eğitim: Sorunlar ve firsatlar. Electronic Turkish Studies, 15(4).

Senemoğlu, N. (2013). Gelişim, öğrenme ve öğretim. Yarg1 Yayınevi.

Saygıll, D., ve Kana, F. (2018). Yabancı dil olarak Türkçe öğreten öğretmenlerin kültürlerarası duyarlılı̆̆ı. Ana Dili Eğitimi Dergisi, 6(4), 1041-1063.

S1lay, N. (2013). A survey of values education and its connection with character education. Academic Journal of Interdisciplinary Studies, 2(3), 131-138.

Sudartini, S. (2012). Inserting local culture in English language teaching to promote character education. Jurnal Pendidikan Parakter, 1, 45-54.

Şişman, M. (2002). Örgüt kültürü̈. Anadolu Üniversitesi Eğitim Fakültesi Yayınları.

Thornberg, R. (2008). The lack of professional knowledge in values education. Teaching and Teacher Education, 24(7), 1791-1798.

Türkben, T. (2019). Türkçe ders kitaplarındaki metinlerin ilettiği değerler açısından incelenmesi. Ana Dili Eğitimi Dergisi, 7(3), 508-526.

Türk Dil Kurumu (TDK). (2010). Türkçe sözlük. Türk Dil Kurumu Yayını

Ulusoy, K., ve Dilmaç, B. (2016). Değerler eğitimi. Pegem Yayıncılık.

Uzun, M., ve Köse, A. (2017). Okul öncesi eğitimde değerler eğitiminin uygulanmasına yönelik öğretmen görüşleri. Bayburt Eğitim Fakültesi Dergisi, 12(23), 305-338. 
Ünsal, Y., ve Güneş, B. (2004). Bir kitap inceleme çalışması örneği olarak MEB lise 1. sınıf fizik ders kitabının eleştirel olarak incelenmesi. Türk Ĕ̈itim Bilimleri Dergisi, 2(3), 305-321.

Wu, S. M., \& Navera, G. S. (2018). ELT materials as sites of values education: a preliminary observation of secondary school materials. In Situating moral and cultural values in elt materials (pp. 51-68). Springer, Cham.

Yalçın, Ş. (2013). İçerik temelli yabancı dil öğretim modeli. Boğaziçi Üniversitesi Ĕ̈itim Dergisi, 30(2), 107-121.

Yalçın, M., Genç, G., Orhon, Ö. ve Şahin, H. (2018). Ortaokul İngilizce 5. sınıf ders kitabı. Milli Eğitim Bakanlığı.

Yazıcı, M. (2013). Toplumsal değişim ve sosyal değerler. Electronic Turkish Studies, 8(8), 1489-1501.

Yıldırım, A., ve Şimşek, H. (2013). Sosyal bilimlerde nitel araştırma yöntemleri. Ankara: Seçkin Yayıncılık.

Yiğittir, S., ve Öcal, A. (2011). Lise tarih öğretmenlerinin değerler ve değerler eğitimi konusundaki görüşleri. Karamanoğlu Mehmetbey Üniversitesi Sosyal ve Ekonomik Araştırmalar Dergisi, 2011(1), 117-124.

Zhu, C. (2011). Students' understanding of values diversity: an examination of the process and outcomes of values communication in English lessons in a high school in mainland China (Doctoral Dissertation) University of Huddersfield. 


\section{Values Covered in the 5th Grade English Textbook and English Teachers' Viwes on Values Education}

Saime GÜL, Teacher.

Erbaa Imam Hatip Secondary School, Tokat / Turkey

saime_gul05@hotmail.com

https://orcid.org/0000-0002-8417-2277

F. Özge MAVISŞ SEVIM, Corresponding Author, Assistant Professor.

Tokat Gaziosmanpaşa University, Faculty of Education, Tokat / Turkey.

ozge.mavis@gop.edu.tr

https://orcid.org/0000-0002-4120-5374

Article Type: Research Article

https://doi.org/10.34234/ded.857721

Received Date: 27.06 .2021

Accepted Date: 03.11.2021

Published Date: 25.12 .2021

\section{Introduction}

It is a well-known fact that one of the most basic aims of education is to raise better individuals. The issue of what is good or better for society is handled differently in different societies, and what is attributed to the concept of 'good' varies according to the values of the society. Aspin (2000), who associates values with concepts such as attitude, action, belief, consciousness, ethics, morality, principle, rights and wrongs, uses values education concept raise the awareness of young people about values, the ability to relate to other people, and to wisely apply values and rules. Values education, which also known as moral education 
or character education, refers to the utilization of pedagogies and structures that ensure the development of positive and ethical social behaviors and competencies in young people (Berkowitz, 2011). Textbooks have an important place in the realization of values education. However, although English lessons are one of the important lessons in values education in terms of presenting both social and universal values through concept-based teaching (Raith, 2017; Wu \& Navera, 2018; Zhu, 2011). Since teachers have a great importance in values education, there are many studies conducted related to values education and teachers (Batmaz \& Erdoğan, 2019; Bayırl1, et al., 2020; Hansen, 2008; Maaranen, et al., 2019; Özleş, 2019; Thornberg, 2008). On the other hand, very few studies are conducted on English textbooks in Turkey, and even fewer of them focus on the opinions of English teachers on values education. Therefore, it is hoped that this study, in which the opinions of English teachers will be determined by examining the textbook of $5^{\text {th }}$ grade, will contribute to the literature in terms of providing more detailed information. The reason for selecting $5^{\text {th }}$ graders is that the students are in the age group at which formal operational stage begins according to Piaget's theory and this stage is considered as suitable for transferring values and beliefs to the students. Also, in the curriculum of the $5^{\text {th }}$ graders, it is aimed to teach the students to use English in their daily life, so values education can be transferred more easily through these daily life conversations. For these reasons, the aim of this research is to analyze the Middle School $5^{\text {th }}$ grade "Happy English" Textbook in the context of values and to reveal the views of English teachers about values education. For this purpose, answers to the following questions are sought:

1. What are the values in the $5^{\text {th }}$ grade English "Happy English" Textbook?

2. What are the opinions of English teachers about the necessity of values education in English education?

3. What are the teachers' views on the adequacy and effectiveness of the activities, contents and visuals in $5^{\text {th }}$ grade textbook for values education?

4. Which values do the teachers think should be given primarily in $5^{\text {th }}$ grade English textbook?

5. What kinds of difficulties do the teachers experience while transferring the values in the textbook to the students? 


\section{Method}

Qualitative research method and basic qualitative research design were used in the research. The "Happy English" textbook (Ceylan, et al., 2019), which was written based on the English curriculum of 2019 and approved by the Ministry of National Education (MoNE) for the $5^{\text {th }}$ grade, was examined on the basis of units. In addition, considering the gap in the literature regrading English teachers' opinions, we collected the opinions of the $5^{\text {th }}$ grade English teachers on values education with open-ended survey questions. In the first part of the research, document analysis method was employed to analyze the $5^{\text {th }}$ grade textbook. For the second part, data were obtained through semi-structured questionnaires. The study group consists of 40 English teachers working in educational institutions affiliated with the MoNE of Turkey in the 2020-2021 academic year. Descriptive analysis was used in the analysis of the data.

\section{Results, Discussion and Suggestions}

According to the results of the research, only one teacher stated that he did not see the need for values education in the English lesson, while the others stated that values education should be included in English lessons for different reasons. It was stated that values education was necessary in terms of recognizing, understanding and respecting cultures and at the same time it had an important place in terms of the students' acquisition of their own national and spiritual values. Similar findings are also emphasized in different studies (Chinh, 2013; Cruz, 2010; Izadpanah, 2011; Sudartini, 2012). Providing personality and character development is another point that teachers consider important regarding values education. In fact, different studies have indicated that values education has impact on the character development of students (Freakley, 2006; Livo, 2003; S1lay, 2013). In addition, teachers thought that values education had a special place in English lessons in terms of raising interest towards the lessons, internalizing the values and ensuring their transformation to behavior, peace, happiness and development of the society, and facilitating the understanding of the universality of values. Also, they stated that teaching new values with a new language would lead to more effective results, and also values education could reduce crime rates and gives students positive attitudes and behaviors. There are studies in the literature stating that language lessons can be integrated with the curriculum and thus students will be able to contribute to the society in terms of 
values (Başaranol, 2017; Ratih, 2017; Zhu, 2011). All these findings reveal how important the values education is in English course and, due to this importance, the teaching of values in the curriculum should be given importance.

A total of 33 values included in the $5^{\text {th }}$ grade English textbook. Values such as friendship, healthy life, sportsmanship, helpfulness and kindness are among the most frequent ones that included. However, there are very few data on values such as justice, honesty, love, respect, patriotism and self-control, which the MoNE emphasizes in English curriculum. Among the findings of this study, it is seen that the majority of teachers give priority to the value of respect. In addition to the value of respect/self-esteem, teachers have expressed values such as love, tolerance and peace, protecting national values, empathy, which are included in the curriculum but are relatively less included in the book, so they think those values should also be included. Considering the examination of the textbook, the findings of the previous book review studies (Aslan, 2019; Aydın $\&$ Can Aran, 2020) and the opinions of the teachers, it is possible to say that English textbook does not fully reflect the spirit of the English Curriculum. As a matter of fact, the majority of English teachers participating in the study think that the activities, content and visuals for values education in English textbooks are not sufficient. For this reason, it could be suggested that all values should be given importance and included at desired level in the textbooks.

Teachers stated that they encountered some difficulties while conducting values education activities. The first difficulty is the lack of effectiveness of textbooks. Another problem is that the values are not included enough due to the curriculum density. Similarly, there are studies stating that values education cannot be included in different fields and courses at the desired level due to the curricula (Cice \& Özgan, 2017; Polat, et al., 2019; Sağlam, 2016). In this sense, it can be said that reducing the subject density in the units or giving the subject content in the units with activities that contain various values may be important for the values education to be carried out more effectively. In addition, the suggestions offered by the teachers within the scope of the study, such as developing materials that will provide additional activities in the context of values education, making the books more qualified in terms of values education, including more values education in the curricula, making project assignments under the values education can be useful. Also, social responsibility projects such as animal shelters, nursing home visits, aid campaigns, collaborative work and activities that will provide learning by having fun can enable students to learn values by doing and living. 
The reasons such as not being able to get support from families in values education and the fact that some students have come across certain values for the first time at school were among the problems stated by the teachers. Being in contact with the families/receiving support in order to carry out values education in an effective way is also most mentioned among the suggestions of teachers. Based on these findings, it is tenable to state that family education should also be included in teaching of values. Other difficulties pointed out by teachers included the difficulty engaging students with different cultures and in addressing cultural differences. For this reason, teachers suggested that both our own culture and the culture of the target language should be included in the course. In addition, the differences between the students can cause teachers to have difficulties in teaching values because some students may have difficulty in embodying, internalizing and applying some values. In this sense, teachers need to be aware of their own culture and values, also the target culture and values. Also, they should know how to conduct teaching activities to students of different ages and cultural backgrounds. For this reason, it will be important to inform prospective teachers about values and values education in pre-service courses. A teacher stated that they had been conducting distance education activities recently due to the pandemic and this situation had caused difficulties in values education. It is seen that many studies that mention the effects of Covid-19 process on education have started to take place in the literature (Bozkurt, 2020; Bektaş-Bedir \& Bedir, 2021; Can, 2020; Daniel, 2020; Mishra, et al., 2020; Sar1 \& Nayır, 2020). However, a study on the relationship between the pandemic process and values education has not yet been found in the literature. Indeed, further studies on this subject will be important in terms of adding to the scientific knowledge about values education during the pandemic process.

Etik Beyan / Ethical Statement: Bu çalışmanın hazırlanma sürecinde bilimsel ve etik ilkelere uyulduğu ve yararlanılan tüm çalışmaların kaynakçada belirtildiği beyan olunur. / It is declared that scientific and ethical principles have been followed while carrying out and writing this study and that all the sources used have been properly cited.

Finansman / Funding: Yazarlar, bu araştırmayı desteklemek için herhangi bir dış fon almadıklarını kabul ederler. / The authors acknowledge that they recevied no external funding in support of this research. 
Yazar (lar) / Author (s): Saime GÜL, F.Özge MAVIŞ SEVIMM

Yazar Katkıları / Author Contributions: Saime GÜL (\%60), F.Özge MAVIŞ SEVIM (\%40)

Çıkar Çatışması / Competing Interests: Yazarlar, çıkar çatışması olmadığını beyan ederler. / The authors declare that they have no competing interests. 